Portland State University

PDXScholar

\title{
How Can Interdisciplinary Teams Leverage Emerging Technologies To Respond To Transportation Infrastructure Needs? A Mixed-Methods Evaluation of Civil Engineers, Urban Planners, and Social \\ Workers' Perspectives
}

Noelle Fields

University of Texas, Arlington

Courtney Cronley

University of Texas, Arlington

Kate Hyun

Enllowethis thandeadditional works at: https://pdxscholar.library.pdx.edu/trec_reports

Part of the Transportation Commons, Urban Studies Commons, and the Urban Studies and Planning Stephen Mattingly

University of Texas, Arlington

Let us know how access to this document benefits you.

Vivian J. Miller

University of Texas, Arlington

Recommended Citation

Fields, Noelle; Cronley, Courtney; Hyun, Kate; Mattingly, Stephen; Miller, Vivian J.; Nargesi, Saeed Reza

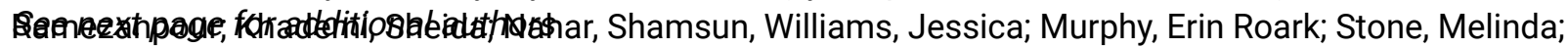
Wattron, Vanessa. How Interdisciplinary Teams Leverage Emerging Technologies to Responed to Transportation Infrastructure Needs? A Mixed-Methods Evaluation of Civil Engineers, Urban Planning, and Social Workers' Perspectives. NITC-RR-1176. Portland, OR: Transportation Research and Education Center (TREC), 2019. https://doi.org/10.15760/trec.220

This Report is brought to you for free and open access. It has been accepted for inclusion in TREC Final Reports by an authorized administrator of PDXScholar. Please contact us if we can make this document more accessible: pdxscholar@pdx.edu. 


\section{Authors}

Noelle Fields, Courtney Cronley, Kate Hyun, Stephen Mattingly, Vivian J. Miller, Saeed Reza Ramezanpour Nargesi, Sheida Khademi, Shamsun Nahar, Jessica Williams, Erin Roark Murphy, Melinda Kitchens, and Vanessa Wattron 

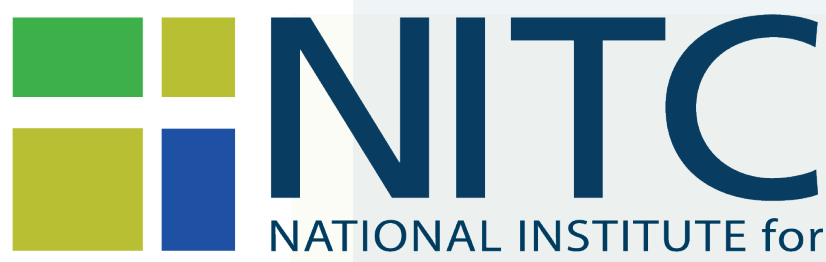

NATIONAL INSTITUTE for

TRANSPORTATION and COMMUNITIES

\section{FINAL REPORT}

How Can Interdisciplinary Teams Leverage Emerging Technologies To Respond To Transportation Infrastructure Needs?

A Mixed-Methods Evaluation of Civil Engineers, Urban Planners, and Social Workers' Perspectives

NITC-RR-1176 April 2019

NITC is a U.S. Department of Transportation national university transportation center.

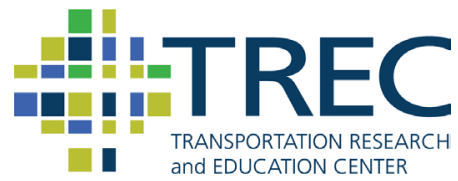




\title{
HOW CAN INTERDISCIPLINARY TEAMS LEVERAGE EMERGING TECHNOLOGIES TO RESPOND TO TRANSPORTATION INFRASTRUCTURE NEEDS? A MIXED-METHODS EVALUATION OF CIVIL ENGINEERS, URBAN PLANNING, AND SOCIAL WORKERS' PERSPECTIVES
}

Final Report

NITC-RR-1176

\author{
by \\ Noelle Fields \\ Courtney Cronley \\ Kate Hyun \\ Stephen Mattingly \\ Vivian J. Miller \\ Saeed Reza Ramezanpour Nargesi \\ Sheida Khademi \\ Shamsun Nahar \\ Jessica Williams \\ Erin Roark Murphy \\ Melinda Kitchens \\ Vanessa Wattron \\ University of Texas at Arlington
}

for

National Institute for Transportation and Communities (NITC)

P.O. Box 751

Portland, OR 97207
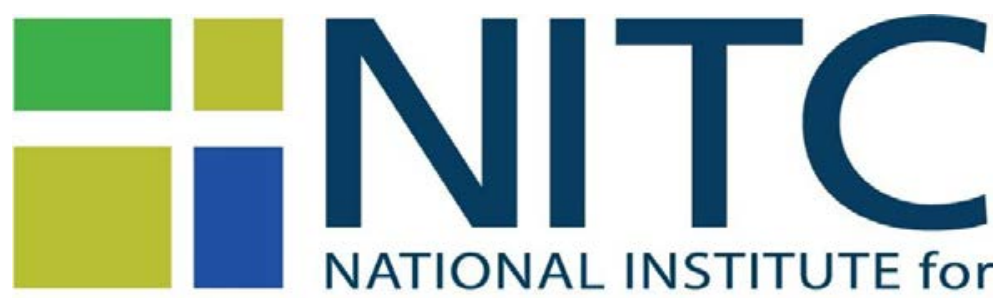

TRANSPORTATION and COMMUNITIES

April 2019 


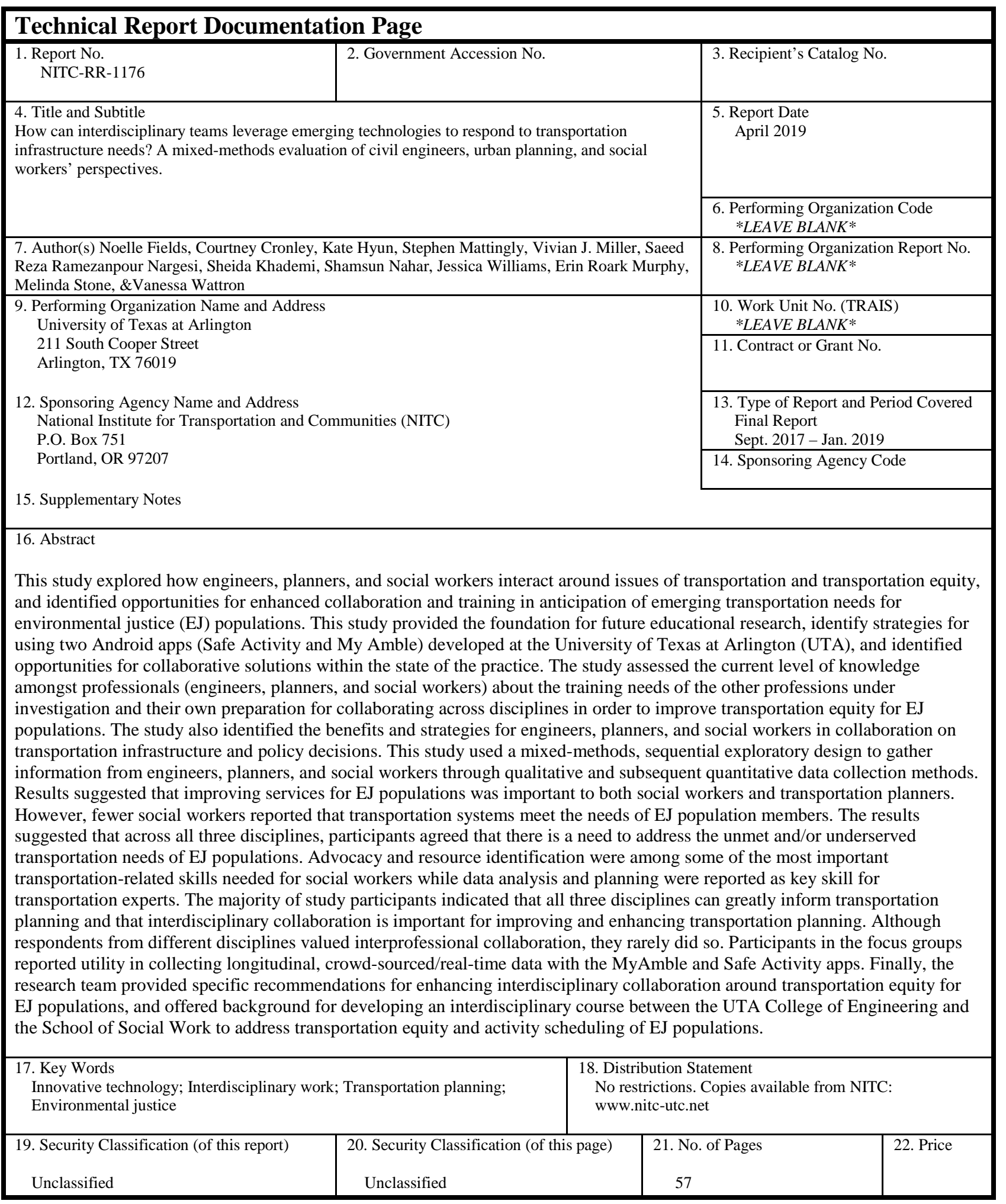




\section{ACKNOWLEDGEMENTS}

This project was funded by the National Institute for Transportation and Communities (NITC; grant number 1176), a U.S. DOT University Transportation Center.

The authors would also like to acknowledge partial support from the Department of Civil Engineering, the School of Social Work, and the Office of Research at University of Texas at Arlington.

\section{DISCLAIMER}

The contents of this report reflect the views of the authors, who are solely responsible for the facts and the accuracy of the material and information presented herein. This document is disseminated under the sponsorship of the U.S. Department of Transportation University Transportation Centers Program and the University of Texas at Arlington in the interest of information exchange. The U.S. Government and the University of Texas at Arlington assumes no liability for the contents or use thereof. The contents do not necessarily reflect the official views of the U.S. Government and the University of Texas at Arlington. This report does not constitute a standard, specification, or regulation.

\section{RECOMMENDED CITATION}

Fields, Noelle; Cronley, Courtney; Hyun, Kate; Mattingly, Stephen; Miller, Vivian J.; Nargesi, Saeed Reza Ramezanpour; Khademi, Sheida; Nahar, Shamsun, Williams, Jessica; Murphy, Erin Roark; Stone, Melinda; Wattron, Vanessa. How Interdisciplinary Teams Leverage Emerging Technologies to Responed to Transportation Infrastructure Needs? A Mixed-Methods Evaluation of Civil Engineers, Urban Planning, and Social Workers' Perspectives. NITC-RR-1176.

Portland, OR: Transportation Research and Education Center (TREC), 2019. 
TABLE OF CONTENTS

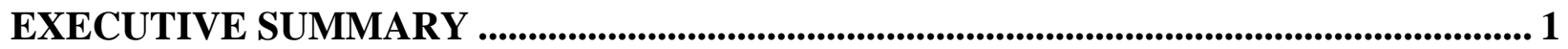

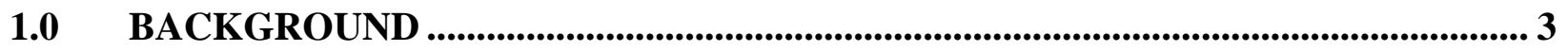

2.0 METHODOLOGY …....................................................................................................... 6

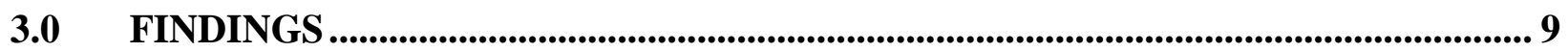

3.1.1 Demographics Information of Focus Group Participants ............................................ 9

3.1.2 Data Analysis ..................................................................................................... 10

3.1.2.1 Professions' Views on Working Across Disciplines ............................................. 11

3.1.2.1.1 QUALITATIVE RESULTS …………................................................. 11

3.1.2.1.2 QUANTITATIVE RESULTS .............................................................. 18

3.1.2.2 User Feedback on Utilizing Mobile Device Apps................................................ 24

3.1.2.2.1 QUALITATIVE........................................................................................... 24

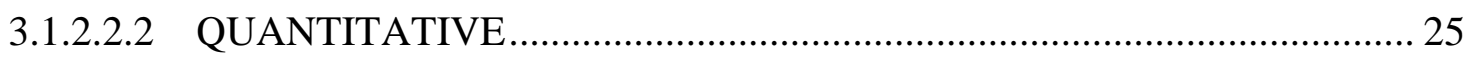

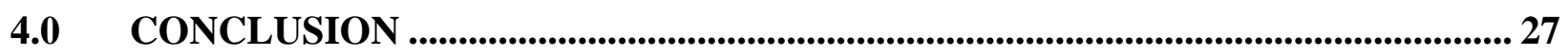

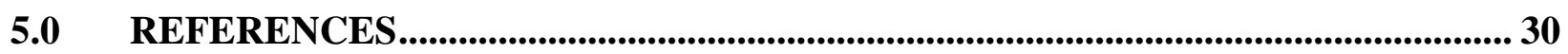

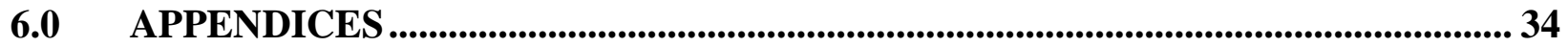

\section{APPENDICES}

APPENDIX A: UNIVERSITY INSTITUTIONAL REVIEW BOARD APPROVAL APPENDIX B: UNIVERSITY APPROVED INFORMED CONSENT APPENDIX C: FOCUS GROUP RECRUITMENT SCRIPT

APPENDIX D: DEMOGRAPHIC AND FOCUS GROUP QUESTIONS

APPENDIX E: PHASE 2, SMALL STARTS SURVEY

\section{LIST OF TABLES}

Table 3.1.1.1: Demographic Information of All Focus Group Participants

Table 3.1.1.2: Demographic Information of Survey Participants

Table 3.1.2.1: Experts' Opinions: Do Transportation Systems Meet the Needs of EJ Populations

Table 3.1.2.2: Transportation-Related Knowledge (a) and Skills (b)

Table 3.1.2.3: Professions Informing Transportation System Planning

Table 3.1.2.4: Strategies for Improving Transportation Planning

Table 3.1.2.5: Interactions Between Social Workers with Other Professions

Table 3.1.2.6: Interactions Between Transportation Experts (Civil Engineers/Transportation Planners) with Other Disciplines

Table 3.1.2.7: Importance of Interdisciplinary Collaboration

Table 3.1.2.8: Context of Professional Interactions

Table 3.1.2.9: Transportation Infrastructure and Policy with Interdisciplinary Collaboration

Table 3.1.2.10: Interdisciplinary Courses Useful for Undergraduate and Graduate Studies

Table 3.1.2.11: Interdisciplinary Options in Undergraduate or Graduate Education

Table 3.1.2.12: Ranking of Features for a Mobile Device App that Collects Transportation Activity Data 


\section{EXECUTIVE SUMMARY}

This study sought to lay the foundation for future educational research, identify strategies for using two Android apps (Safe Activity and My Amble) developed at the University of Texas at Arlington (UTA), and identify opportunities for collaborative solutions within the state of the practice. This study used focus groups and an online survey to gather this input. This study utilized a mixed-methods, sequential exploratory design that employed an initial phase of qualitative data collection and analysis followed by a phase of quantitative data collection and analysis.

A total of 27 individuals $(\mathrm{N}=27)$ participated across six focus groups. Participants' professions included social work $(33.3 \%, 10)$, transportation planner $(30 \%, 9)$, and civil engineer $(10 \%, 3)$. The researcher asked participants a series of open-ended questions intended to collect qualitative feedback regarding: what skills/knowledge regarding transportation systems and users engineers, planners, and social workers require in their profession; the extent to which each of these professions interact regarding transportation infrastructure and policy; the extent that these professions could utilize data features within Safe Activity and MyAmble to accomplish their jobs most effectively; and, the benefits that each professional sees for interacting with other disciplines/professions when making transportation infrastructure and policy decisions.

Advocacy, information gathering, referral/brokering services, and policy/data were identified as the skills/knowledge needed regarding transportation systems. Participants reported that they interact with other disciplines through organizational or agency meetings as well as through advisory boards and/or advisory groups. However, many participants also noted that the extent to which they interact with one another was very limited and that disciplines were "siloed." Two themes emerged from the data related to the data and features within the apps: collecting longitudinal data and crowd-sourced/real-time data. All three disciplines identified the utility of these features. Three themes emerged from the data related to collaboration: improving services for EJ populations, enhanced understanding of other disciplines, and enhancing future research and planning. The findings from these focus groups were a result of a mutual agreement reached during the follow-up meeting and were subsequently used to inform the quantitative survey that was implemented as the second phase of this study.

In the second phase, the study administered an electronic survey using Qualtrics. The researchers recruited survey participants through professional networks and organizations such the National Institute for Transportation and Communities, the Transportation Research Center for Livable Communities, the North Central Texas Council of Governments, as well as through listservs at the University of Texas at Arlington School of Social Work. The survey was used to develop a broader consensus about the themes and strategies identified in the focus groups.

The respondents $(\mathrm{N}=177)$ first answered if they think transportation systems meet the needs of diverse populations, particularly individuals who are lower-income, older, or disabled. 
Transportation systems are considered to meet the needs of EJ communities to a small (40\%) or some (29\%) extent by social workers while transportation experts thought the needs meet to a moderate (31\%) or some (31\%) extent. Available resources, transportation infrastructure or policy, and information on disadvantaged or at-risk populations were identified as the most important knowledge for social workers, transportation experts, and others, respectively. As the most important skills, advocacy was chosen by social workers while data analysis and public engagement were selected by transportation experts and others. In addition, research design (transportation planner), resource identification and provision for self-education (social worker) were specified as the important transportation-related skills.

Many of the professionals (70\% of social workers, 53\% of transportation experts and $76 \%$ of others) reported that all the disciplines can inform transportation system planning to a great or a very great extent. Community engagement, data collection, and advocacy efforts were the top three strategies that social workers consider to be important for improving transportation planning while data collection, developing comprehensive performance measures, and community engagement were identified as the most important three strategies for transportation experts. The results indicate that $78 \%$ of social workers and $41 \%$ of transportation experts never work with transportation experts and social workers, respectively.

The respondents evaluated each feature of two apps, Safe Activity and My Amble, and indicated how much the feature would be helpful to collect transportation activity data.

The top three rated features selected by social workers were "open-ended question," "multilingual text," and "regional transportation information." For the transportation experts, however, the features related to accurate data collection such as "Interactive map with GPS," "GPS pinpoint user locations," and "features that capture longitudinal data" were chosen as the most important features.

Finally, the respondents answered how beneficial they think an interdisciplinary course related to transportation in their undergraduate or graduate studies would have been for their current work. A total of $35.1 \%$ and $31.1 \%$ of social workers believe that the transportation-related interdisciplinary course would have been somewhat or very helpful, respectively. The majority of transportation experts (87.5\%) also positively evaluated their interdisciplinary courses while $54.5 \%$ of other professionals reported the course would have been helpful.

The study has notable strengths. First, the mixed-method design allowed us to both measure the degree to which professionals across disciplines recognize a need for interprofessional approaches to addressing transportation, as well as the quality of this recognition. There were some limitations to the study results. First, despite intentional outreach across all three disciplines, respondents to the quantitative survey were overwhelmingly social workers. Second, the uneven distribution of respondents in the survey made testing for group differences across the three professions unfeasible. Finally, the low response rates in transportation planning and engineering mean that these results may not be generalized to the professions overall.

In conclusion, the qualitative data suggests that improving services for EJ populations was important to both social workers and transportation planners. Findings suggest that advocacy and resource identification were among some of the most important transportation-related skills 
needed for social workers while data analysis and planning were reported as key skills for transportation experts. The majority of study participants indicated that all three disciplines can greatly inform transportation planning and that interdisciplinary collaboration is important for improving and enhancing transportation planning. While respondents from different disciplines valued interprofessional collaboration, they rarely did so.

Although each discipline differed in what was deemed as most useful in the apps, findings suggest overall that MyAmble and Safe Activity offer promise in collecting meaningful data for both social workers and transportation experts. Finally, given that study findings suggest that interdisciplinary collaboration is welcomed and needed among social workers and transportation experts, the future design of a graduate-level seminar taught by faculty in social work, planning, and civil engineering seems warranted.

\subsection{BACKGROUND}

Although there is increasing attention paid towards the importance of interdisciplinary research, and interdisciplinary education across higher education, there still exists scant research specifically between the fields of social work, engineering, architecture, and technology (1). Barriers across disciplines can not only create obstacles and challenges for students, but can perpetuate silos of research, limiting the potential and possibilities of solving complex and significant social challenges (2). Interdisciplinary research, particularly, is project based and incorporates existing conceptual models and theoretical frameworks into the ongoing, iterative research process $(3,4)$. The benefits of carrying out projects across disciplines and professions, as cited in Miller et al. (5), "requires the greatest synthesis of approach...Teams not only share a common question, but also often share and borrow methods, create a common conceptual framework, and either learn each other's disciplinary language or create a new common language” (6). It is through these interdisciplinary projects and active engagement across professions that scholars can investigate, explore, design, and implement research that benefits the quality of life and well-being for at-risk populations. Enclosed in this report is a project that seeks to explore the current relationships and interactions between engineers, planners, and social workers, and to identify opportunities for collaboration and improved training for the future.

Transportation mobility is critical for livable communities and is the vehicle that facilitates social engagement, communication and information, civic participation, employment, housing, health 
and community, respect and inclusion (7). Persons identified as environmental justice (EJ) populations (e.g., older adults, persons of low income, low socioeconomic status, racial and ethnic minorities, and individuals with disabilities) are at an increased risk for transportation disadvantage (8) and may experience an increase in barriers related to overall quality of life and well-being due to these compounding factors.

While transportation planners and engineers seek to address the needs of EJ populations in their solutions, they may not have sufficient preparation to evaluate the impacts of different strategies on all community members. Similarly, social workers, with the awareness of the impact transportation has on their client populations, may not be aware of the decision-making processes and broader approaches used to develop transportation solutions, or the costs associated with these solutions. Each of these professions, together with the common goal of improving the quality of life for disadvantaged populations, can work synergistically to tackle social justice issues.

\section{Examples of interdisciplinary work to address transportation needs of community members}

Previous research has sought to examine the nature of interdisciplinary work across higher education, specifically focusing on transportation planners, civil engineering, and social work. Two examples of these interdisciplinary projects include the development of mobile device applications: Safe Activity and MyAmble. The following literature provides background on these two projects, as this will provide a context for the current study.

\section{Safe Activity app}

Safe Activity is a mobile device app, developed for Andoid devices, that utilizes crowdsourcing in order to generate mass data about potential safety issues from a pedestrian's or bicyclist's point of view. If and when an app user faces a near miss or potential conflict while engaging in an outdoor activity, he or she may log into Safe Activity and follow the simple question and answer format in order to generate a severity index for his or her specific incident. Once this information has been submitted, it is stored in Amazon Cloud and formatted into files that can be used by municipalities and transportation planners for further research. The app not only uses crowdsourcing as a form of data retrieval, but it also allows the users to see conflicts that have been logged by other users, which in return crowdsources knowledge about the safety issues that are present near them.

\section{MyAmble app}

MyAmble is a mobile device app that was developed by faculty and students across the School of Social Work, Department of Civil Engineering, and Department of Computer Science. The overall purpose of this app was designed to measure the impact of transportation disadvantage on quality of life and social exclusion among at-risk populations. This complementary multidisciplinary composition of social science and engineering team members allowed for a more holistic perspective and comprehensive approach to problem solving, integrating the theories of human behavior and the human experience into transportation planning and leveraging novel technologies (9). 
The app, MyAmble, contains four components. During the development of the app, civil engineering members focused on technical app flowcharts, social work students focused heavily on the features that encourage participants to document their transportation plans and daily schedules. Moreover, social work student team members developed the interview schedules and questionnaires, which would later be embedded within the app. Social work faculty and students organized the qualitative data collection features of the app along a theoretical framework of the following domains of social exclusion (10): (1) resources (e.g., material/economic, public/private, social), (2) participation (e.g., social, cultural, education, skills, political, civic), and (3) quality of life (e.g., health, well-being). Social workers are especially suited to develop safe, positive client-worker relationships that uphold the professional responsibilities to understand the worth and dignity of every individual and to maintain confidentiality. Social work student team members also contributed to the app design, with specific focus on usability by older adults, for example considering the size of the tablet device and the visibility of text, as well as dexterity issues related to use of the keyboard. On social work students and faculty recommendation, the team included an expansive audio recording option so that participants could choose to type or speak into the device when recording their data. Overall, the study sought to examine transportation mobility experiences and their impact on quality of life of transportation disadvatanged older adults.

To explore the roles across disciplines, the following three research questions guided this study:

- What skills/knowledge regarding transportation systems and users do engineers, planners, and social workers require in their profession?

- To what extent do engineers, planners, and social workers interact regarding transportation infrastructure and policy?

- To what extent could engineers, planners, and social workers utilize the data and features within Safe Activity and My Amble to accomplish their jobs more effectively?

- What benefits do professionals see for engineers, planners, and social workers to interact when making transportation infrastructure and policy decisions? 


\subsection{METHODOLOGY}

This study sought to lay the foundation for future educational research, identify strategies for using two Android apps (Safe Activity and MyAmble) developed at the University of Texas at Arlington (UTA), and identify opportunities for collaborative solutions within the state of the practice. This requires gathering responses from engineers, planners, and social workers. This study used focus groups and an online survey to gather this input. Before conducting both the survey and focus group, the research team received UTA Institutional Review Board (IRB) approval for human subjects. This study utilized a mixed-method, sequential exploratory design that employed an initial phase of qualitative data collection and analysis followed by a phase of quantitative data collection and analysis (11).

This two-phase design included: (1) focus groups to identify common themes that (2) were investigated in more specific detail in a subsequent quantitative survey. The focus groups were used to collect in-depth responses to the aforementioned research questions and to explore potential ideas for the outcomes. The focus groups utilized semi-structured, open-ended questions in order to elicit explanations, descriptions, and/or illustrations from study participants (12). The focus groups were interdisciplinary and contained engineers, planners, and social workers. Members of the research team recruited participants for the focus groups through purposive and snowball sampling methods.

Focus group participants were recruited through local community organizations. Emails containing the study recruitment script and respective University of Texas at Arlington Institutional Review Board approval number were disseminated to local community organizations, including social service organizations (e.g., Arlington Life Shelter, the Senior Source, Meals on Wheels, etc.), local council on governments (e.g., North Central Texas Council on Government), and metropolitan planning organizations. Social work and social service participants served in a variety of roles including case management, Chief Operations Officer, and program director. Transportation planning and civil engineering participants' roles included staff positions at county transit agencies and transit authorities.

Interested participants replied to the researcher and signed up for a focus group (one of six in total) of their choosing. Participation was voluntary and each participant gave their informed consent before engaging in any of this study.

Each participant was offered gift cards as incentives/compensation for their time. Each focus group contained a maximum of 12 participants per group (13). Focus groups each lasted roughly 60 minutes. One member of the research team (faculty) moderated the focus group while another member (research assistant) served as the observer/note taker. Each focus group was held virtually, using Zoom.us a conference platform. The audio of each virtual focus group was recorded and transcribed verbatim. Focus group data were analyzed using a directed content analysis approach in order to avoid preconceived categories and to allow for categories to flow from the data (14). To examine participant perspectives across the disciplines of social work, 
civil engineering, and transportation planning, individuals participated in focus groups that utilized open-ended questions. The researcher asked participants a series of open-ended questions intended to collect qualitative feedback regarding: what skills/knowledge regarding transportation systems and users engineers, planners, and social workers require in their profession; the extent to which each of these professions interact regarding transportation infrastructure and policy; the extent that these professions could utilize data features within Safe Activity and MyAmble to accomplish their jobs most effectively; and, the benefits that each professional sees for interacting with other disciplines/professions when making transportation infrastructure and policy decisions. Additionally, participants were asked probes following openended questions. Standard qualitative research approaches suggest that probing is a technique that allows researchers and interviewers to "generate further explanation from research participants" (15). Each participant has been anonymized where just an initial is used to identify respective quotes.

In the second phase, the study administered an electronic survey using Qualtrics. Web-based surveys offer several advantages in terms of cost and time efficiency (16). Survey questions included items pertaining to the degree to which transportation systems meet the needs of diverse and vulnerable populations as well as what type of transportation-related skills and knowledge were important for the participants' respective professions. Questions related to interdisciplinary interaction and interdisciplinary coursework opportunities were also included. Additionally, survey questions pertaining to the functionality of mobile device app features (MyAmble and Safe Activity) were asked of participants. A copy of the survey is attached in the Appendices.

A total of 129 participants were surveyed. Emails containing the study recruitment script and respective University of Texas at Arlington Institutional Review Board approval number were disseminated to professional societies such as the American Planning Association, Institute of Professional Engineers, and National Association of Social Workers (NASW). The membership rosters of these organizations offered a great initial resource. The research team also targeted large organizations affiliated with NITC such as Tri-Met, or large local organizations such as the North Central Texas Council of Governments, as well as state and regional chapters of NASW. In addition, emails were sent to listservs maintained by the UTA School of Social Work containing a vast network of professional social workers in the region. By utilizing these professional societies and academic institutions, whose affiliates are representative of the respective disciplines (e.g., planning, engineering, and social work), we hoped to generate a representative sample across the populations.

Moreover, the researchers minimized the typical challenges to representation associated with electronic surveys by following best practices (17), such as relying on opinion leaders to disseminate the surveys, sending frequent reminders, and providing an incentive in the form of entry into a raffle for an Amazon gift card. Finally, because the survey data was largely for descriptive purposes, sample power, which is a consideration in inferential statistical analyses (18), was not relevant. The researchers recruited survey participants through professional networks and organizations such as the National Institute for Transportation and Communities, the Transportation Research Center for Livable Communities, the North Central Texas Council of Governments, as well as through listservs at the University of Texas at Arlington School of Social Work. By utilizing these networks, whose members are representative of the respective 
disciplines (e.g., planning, engineering, and social work), researchers attempted to generate a representative sample across the populations. The survey was used to develop a broader consensus about the themes and strategies identified in the focus groups. 


\subsection{FINDINGS}

\subsubsection{Demographics Information of Focus Group Participants}

A total of 27 individuals $(\mathrm{N}=27)$ participated across six focus groups. Of all participants, a majority were female. Participants' ages were all 26 years and above with an almost equal distribution across ages 31 to 50 years old. A majority of participants self-identified as Caucasian. Across other races, four participants self-identified as African-American/Black, and three as Other (Hispanic; Asian; Other). Education levels varied with nearly half of the participants having a master's degree, next to a doctoral degree, a bachelor's degree, and those who have completed some college. Participants' professions included social work, transportation planner, and civil engineer. Of all individual involved in this study, a few held a professional license, including AICP, child care administrator, juris doctorate by the State Bar of Texas, licensed clinical social worker, licensed master social worker, and professional engineer. Participants were employed at various agencies around the the Dallas/Fort Worth metroplex, which included the metropolitan planning agency, transit authorities, social service providers, private transportation providers, and academics/researchers.

Table 3.1.1.1: Demographic Information of Focus Group Participants

\begin{tabular}{ll}
\hline VARIABLES & $\%(\mathrm{n})$ \\
\hline Gender & $63.3 \%(19)$ \\
\hline Female & $26.7(8)$ \\
\hline Male & $3.3(1)$ \\
\hline Age & $23.3(7)$ \\
\hline $26-30$ years old & $13.3(4)$ \\
\hline $31-35$ years old & $16.7(5)$ \\
\hline $36-40$ years old & $20.0(6)$ \\
\hline $41-45$ years old & $13.3(4)$ \\
\hline 46 -50 years old & \\
\hline 56 or older & $13.3(4)$ \\
\hline Race/Ethnicity & $66.7(20)$ \\
\hline Black/African American & $3.3(1)$ \\
\hline Caucasian & $3.3(1)$ \\
\hline Hispanic & $3.3(1)$ \\
\hline Asian & \\
\hline Other & $3.3(1)$ \\
\hline Highest Level of Education & $20.0(6)$ \\
\hline Completed some college & $40.0(12)$ \\
\hline Bachelor’s degree & $26.7(8)$ \\
\hline Master's degree & \\
\hline Doctoral degree & $33.3(10)$ \\
\hline Professional Discipline & $10.0(3)$ \\
\hline Social Worker & $30.0(9)$ \\
\hline Civil Engineer & $30.0(9)$ \\
\hline Transportation Planner & $60.0(18)$ \\
\hline Have a Professional License &
\end{tabular}


There were a total of 177 participants $(\mathrm{N}=177)$, of which the majority were female $(82.49 \%$, 146). Participants' ages were 18 and above, with an almost equal distribution across age ranges. A majority of participants self-identified as Caucasian $(65.36 \%, 117)$, with the fewest identifying as Indigenous/Aboriginal $(0.56 \%, 1)$. Education levels varied, with most participants $(71.51 \%$, 128) having a master's degree, 22 (12.29\%) a doctoral degree, and 20 (11.17\%) a bachelor's degree. Participants' professions included social work $(74.86 \%, 124)$, civil engineering $(10.06 \%$, 18), transportation planning $(12.29 \%, 22)$, and other (e.g., registered nurse, counselor; $12.29 \%$, 22).

Table 3.1.1.2: Demographic Information of Survey Participants

\begin{tabular}{ll}
\hline VARIABLES & $\%(\mathrm{n})$ \\
\hline Gender & $17.51 \%(31)$ \\
\hline Male & $82.49 \%(146)$ \\
\hline Female & \\
\hline Age & $9.03 \%(16)$ \\
\hline $19-25$ & $19.7 \%(35)$ \\
\hline $26-31$ & $18.6 \%(33)$ \\
\hline $32-37$ & $10.1 \%(18)$ \\
\hline $38-43$ & $11.8 \%(21)$ \\
\hline $44-49$ & $12.4 \%(22)$ \\
\hline $50-55$ & $13.5 \%(24)$ \\
\hline $56+$ & \\
\hline Race/Ethnicity & $0.56 \%(1)$ \\
\hline Arab & $4.48 \%(8)$ \\
\hline Asian/Pacific Islander & $13.41 \%(24)$ \\
\hline African-American/Black & $65.36 \%(117)$ \\
\hline Caucasian & $7.26 \%(13)$ \\
\hline Hispanic & $0.56 \%(1)$ \\
\hline Indigenous/Aboriginal & $1.68 \%(3)$ \\
\hline Latino/a & $3.35 \%(6)$ \\
\hline Multiracial & $2.23 \%(4)$ \\
\hline Other & \\
\hline Highest Level of Education & $4.47 \%(8)$ \\
\hline Some College & $11.17 \%(20)$ \\
\hline Bachelor's degree & $71.51 \%(128)$ \\
\hline Master's degree & $12.29 \%(22)$ \\
\hline Doctoral degree & $0.56 \%(1)$ \\
\hline Professional degree & $74.86 \%(134)$ \\
\hline Professional Discipline & $2.79 \%(8)$ \\
\hline Social Work & $10.06 \%(18)$ \\
\hline Transportation Planner & $12.29 \%(22)$ \\
\hline Civil Engineer & \\
\hline Other (RN, Counselor) & \\
\hline & \\
\hline & \\
\hline
\end{tabular}

\subsubsection{Data Analysis}

This study, guided by four main research questions, had a significant focus on interdisciplinary collaborations and tested the feasibility of two mobile app devices for use in interdisciplinary work. This next section present analyses of findings, first interdisciplinary collaborations, followed by views on the two data collection apps, guided by respective research questions. 
The type of analysis used to study the qualitative data was directed content analysis (14). This analysis approach, sometimes referred to as a deductive analysis (14), is direct and structured (19). This analysis approach was used to begin coding with predetermined codes, which were derived from the existing research questions of this study. After the coding of each focus group transcript was complete, researchers met as a group to discuss the results from each research question. The findings from these focus groups are a result of a mutual agreement reached during the follow-up meeting and were subsequently used to inform the quantitative survey that was implemented as the second phase of this study.

\subsubsection{Professions' Views on Working Across Disciplines}

\subsection{QUALITATIVE RESULTS}

Research Questions 1, 2, and 4 related to an interdisciplinary understanding and knowledge, across the professions of social work, engineers, and planners.

Research Question 1: What skills/knowledge regarding transportation systems and users do engineers, planners, and social workers require in their profession?

Four themes emerged from the data related to advocacy, information gathering, referral/brokering services, and policy/data. Advocacy skills were primarily identified by the social work/social service providers who served EJ populations. Both social work and planners reported information-gathering skills such as collecting community resources and connecting with stakeholders. Referral and brokering services on behalf of clients were identified primarily by social workers/social service providers. Primarily planners and engineers reported understanding policy and analyzing data as part of their professional knowledge and skills.

\section{Advocacy}

One social work focus group participant shared that their role is primarily advocacy, as it relates to transportation. She stated, "So, we just kind of keep advocating for the need to have some form of a free or someone being able to provide that transportation. So, in my role, it's advocacy. Being able to speak that and keep pitching for that” (L). Another social work participant had similar roles in their workplace where they examine and take account public transportation as a need of the clients they serve, sharing: "We advocate many instances where we're trying to match our volunteers with a client. We do have to take into account those who take public transportation and when you look at the distance from where they live to the client that they're serving, it may only be a couple miles away. But, when you look at the bus routes, it's gonna take them an hour to get there and there's no place for them to sit at the bus stop. Even at the end of their journey, they've got a long walk from the bus stop to the client's homes. Those are the kinds of things that we're always looking out for is the welfare of our volunteers and the client that they serve" (M). This was a common thread throughout the social work professional community in advocating for client rides, especially those who experience challenges and difficulties in doing so. Another social worker stated, "I guess my role, I kind of advocate for clients that have difficulty getting rides. So I stay in touch with Handitran and additionally I have an intellectually disabled nephew that is 33 that lives with me, that rides Handitran every day" 
(S). Finally, advocacy was ultimately helping give voices to those who did not have them. Social worker $(\mathrm{H})$ stated that the skills and knowledge needed included, "Knowing your resources, knowing who to go to ask for assistance, knowing like what's current and available in the area, what's coming up, where to go to be a part of the decision making, how to get my residents' voices heard. You know, when surveys come out, making sure that they have access to them, that their putting in their input, encouraging them to attend meetings as well. I think those are the key things we need here.”

\section{Information gathering}

Civil engineers, transportation planners, and social workers each endorsed gathering information as a part of their role in the skillset, knowledge, and information that they needed to know. One transportation planner simply stated, "I think for us it's just knowing what our services are and what we can offer” (K). Another transportation planner states they have to know everything and gather all the information so they can disseminate this to their client population, sharing: "We just kind of have to know most everything but that's because it's kind of the nature of what we do, we're a transportation and information resource. Our funding requires us to focus on seniors and people with disabilities so, I mean there's this whole other world of more job access transportation's that we're not really, I mean I try to keep as much information as I can but technically it's not part of what our program does. It's not a big focus for us, but yeah” (B).

A social worker shared similar thoughts and experiences in needing to know resources, and to keep this knowledge working, where she stated: "I guess for me, the knowledge that I have needed is a working knowledge of the resources that are available in the various communities where I get ... calls from, from individuals who are no longer able to travel independently. And, also, is being able to ... relay the requirements and some of the reasons behind eligibility, expectations and that kind of thing to people in a layman's kind of way to help them understand why they may not qualify or they should've qualified but may have been denied and that they should go back and appeal” (S).

Gathering information on community resources was not the only information gathering necessary for these interdisciplinary professionals to serve clients. One transportation planner shared that they also need to gather information and knowledge directly from the community members, stating: "We as staff, have minimal influence over adding projects to the plan. We could communicate with environmental justice communities to find out what their needs are, but I think the more effective route would be if environmental justice communities could communicate their need to members of the RTC, who are then much more influential in getting projects into the long-range plan" $(\mathrm{K})$. Two social workers found the same to be true in their professions, where one stated: "I want to echo what everyone else said. You have just kind of be resourceful. And that's basically what I kind of do. I push myself to know all the resources, anything that can possibly help any of the people that I encounter” (L), and another shared, “And then being able to go into the communities, because every community is different. It's not a onesize-fits-all. For us, it's been learning the communities and what the communities need. And then start from that standpoint and then go from there" (K).

Some professionals shared that they did this information gathering best through community networks, through both the gathering and delivery of information to address and serve community members in need. One social worker stated: "But one of the interesting things that I've learned so far in my service to the community is networking. I believe that a lot of the services that I am looking for, for my clients, come through networking with other agencies, and 
possibly public transportation agencies. That way they can provide me with the knowledge that I need, so that in return I can provide my clients with what they need” (L). A civil engineer shared the process in which this networking took place, stating: "Typically the determination of what's needed in the future is done through a public process where we have public meetings and people come and say what they need or whatever... we just advertise and talk to whoever comes to the meeting" (J). Finally, another civil engineer stated, very simply, their process: "So we educate, we provide the information, we do the legwork of studying who the stakeholders are, who are the ones at risk, and present that, and so that's the way in which we try to address those [EJ] communities" (C).

\section{Referral/brokering services}

Social workers and persons in similar fields noted that their role includes referring and brokering services to meet the needs of their clients. One social work participant stated: "We help people over the phone, and so we give out a lot of options. Well, there's not a lot of options for transportation, but we refer them a lot to My Ride, which is part of MHME. We've worked together with them in the building, and so they are more knowledgeable about the different systems people have to take to get from one side of town to the next, and go to all their appointments. So we typically work with those transportation navigators to help clients, because they're just a little more knowledgeable about the different options” (B). Another participant, in a similar field (criminal justice), stated that: "Working with the juvenal department to help facilitate whether that's transportation directly from the juvenal department or some type of transportation route that they're using public transit, but helping to find those barriers and then help the, either the service provider or the justice system close that gap” (J).

\section{Policy and data}

The final theme to emerge from the focus groups on what training was needed in their respective profession included policies and data, to assess the needs and understatnd interactions and how larger systems work. One transporation planner stated that: "To be a planner you've got to understand what kinds of services might be appropriate for different kinds of markets. Then you need to be also familiar with the federal regulations, the Title XI regulations, what The Federal Transit Administration requires in terms of doing analysis, doing service changes, making sure that when you make proposed changes that you make that available in languages" (T). Another planner shared that, “...working with state and federal governments on regulatory issues, programs. And legislative affairs. And so that's the kind of background that I'm coming from. I work separate from the county of transportation services” (R). Lastly, a third transportation planner stated, "So I think my role and other people's role is just the knowledge of program management and knowledge of the data. Knowing we really do a deep dive, when any new person starts working here, to understand our transportation needs and our system and how they all interact with each other. So that's kind of the knowledge we bring to the table, in terms of transportation systems and having that comprehensive knowledge, as well as some of the data. The federal programs, the federal safety programs that are available and also some of the analysis methods. So that we design program offering to meet the needs of our communities" (J). A transporation engineer, to understand the scope of the problem for clients served, shared that she needed data to analyze and make deductions, sharing: "To me, as a transportation engineer, I think I'm taking a systematic approach to look at or understand the EJ population transportation obstacles or barriers. So, for example, I ... try to look at the data. I collect the data 
from survey or collect the data from any available sources and see how the transportation activities look like in different groups, in transportation EJ groups or non-EJ groups, in how they react to any policy changing or new transportation systems” (K).

Research Question 2: The second research question, also interdisciplinary in nature, asked: To what extent do engineers, planners, and social workers interact regarding transportation infrastructure and policy?

Several participants reported that they interact with other disciplines through organizational or agency meetings as well as through advisory boards and/or advisory groups. However, many participants also noted that the extent to which they interact with one another was very limited and that disciplines were "siloed."

\section{Organization/agency meetings}

One participant, a transporation planner, stated: "We are very involved with everyone from our mental health district... as well as other hospitals and health care providers. We work extensively with the criminal justice system...we work with all the various players and services of the county and ancillary agencies to provide, so we really get a good feedback across the county" (J). A social worker shared similar organizational culture in the extent that they met with other professions, sharing: “...being a part of our taskforce, we have meetings at the end of every month. And all organizations are at our table. We have several people that are representing transportation. Just about everyone sends a representative. City council, congressman. All these people come out and represent and then we talk about a whole array of issues. But transportation is always at the top of the list” $(\mathrm{L})$. Finally, that same transportation planner endorsed that these agency meetings were in fact interdisciplinary in nature, stating: "Our agency has regular meetings of all kinds with the MPO and the transportation planners there. We discuss funding programs and participate in a lot of interdisciplinary working groups and coalitions there” $(\mathrm{J})$.

\section{Advisory boards/groups}

Participants shared that a significant means of their interacting was accomplished through advisory boards and groups. One participant, a transportation planner, shared: "We have a board, two advisory boards. A technical advisory board with engineers and planners that we will take projects to for approval before going to our regional transportation counsel. That's where elected officials and whatnot sit to then approve projects. So we have formal communications with engineers and planners and professional with that level as well as elected officials. But then also working through our projects. Access for Texas will work social service agencies, workforce, housing... Anyone, essentially, that I can get to talk to, to receive information about gaps in service” (H). Another participant, a social worker, discussed their involvement in an advisory board as a way to interact and engage across professions, stating: "I'm a member of a Peer Transit Accessibility Advisory Group, which ... I guess is more of a planning and reporting back kind of venue than it is a ... you know, talking with engineers or anything. But ... I've had the opportunity to meet with on-cross disability groups to meet the needs of veterans, people who are older, people who have disabilities, that type of thing" $(\mathrm{N})$.

\section{Limited interaction}


While a number of focus group participants highlighted their engagement with other professions, many shared thtat they had limited interactions with each other. One social worker, who stated she does not attent meetings, reported that her interactions were scant, stating: "I'm not the convener of the meetings but ... I can probably count on one finger the number of times I've been in a meeting where engineers have been involved. Usually it's planners and representatives of the varying group ... So I don't feel like I personally would have any access to engineers. But could probably, on my own, get access to some planners, but really the people who convene the meetings that I attend are the ones who have that access” $(\mathrm{N})$. A transportation planner also shared their limited interactions, and how this may impact awareness of community needs, stating: "I mean we have a lot of planners and a lot of engineers with the city but we don't have a lot of social workers and I think we may miss a couple things...particularly the populations that you all are talking about, the subject of the study, there's not a big awareness of that and having an availability to some information about that certainly would be useful” (J). A civil engineer articulated their limited interactions, especially with social work, stating, "Just looking around at what we do, I don't think have as much interaction with like a social work capacity, and again, we're big and there are probably people somewhere dealing with that so I don't want to speak representatively. But it's a big organization” (C).

Finally, two social workers shared that their interaction is limited if non-existant, stating: "I would think the interaction is pretty much nil. I don't recall, I mean the fourteen years I've been with [social service agency], I don't recall any interaction with engineers or anybody that does any planning. I mean I would love to be part of that discussion. I certainly think I could represent a portion of the community that would benefit from transportation, but I have not been in any of those discussions" (S), and another stated, "We really don't. It's just mostly trying to find the best options for the client” (B).

\section{Working in silos}

The final theme to emerge from the second research question was, Working in Silos. Similarly to the theme of Limited Interactions, focus group participants from social work, civil engineering, and a social work-related field reported that worked with their own profession. One participant shared, "I think it's very individualized. There can be one group that's working on reentry services, for example, that they have identified transportation is a barrier, maybe they've reached out and been able to over come some of those. As far as a more systemic ability for one discipline to interact with another, I think that we're still very siloed. Again, I think that it's more about networking and relationship building, not necessarily being able to connect the two systems" (J). Another participant, a civil engineer, shared: "But I would say we definitely have a lot of interaction with engineering side and a lot with ... There's a wide array of transportation related industry, like with intelligent transportation system technology, all sorts of transportation data platforms, so yeah. And there's probably the preponderance is definitely on the industry side” (C). Finally, a social worker voiced their feelings and concerns on the matter of only working within one's own field, stating, "I mean we deal with the frustration of clients who can't benefit from transportation services, but we don't even know who to go to. I personally don't. I wouldn't know who to talk to. I think if it was again an opportunity, I mean I would be glad to be part of that conversation. It's just never been presented to me" and "Yeah, we hear the voices of our clients and we deal with a level of frustration because we're not able to help meet their needs. It really is pretty frustrating because you see the need and you'd love to be able to shout at, to the powers that be, to let them know that this need exists. Why can't we fix this? We don't quite 
know where to direct our voice. We don't know who to communicate that to and so that's ... I think there are definitely multiple organizations that would all come together and we would all pretty much shout the same thing. It's just when does ... Where's the opportunity? When does it present itself?” (S).

The fourth research question also sought to gather information from focus group participants on interdisciplinary work with a focus on perceived benefits. Research Question 4 asked: What benefits do professionals see for engineers, planners, and social workers to interact when making transportation infrastructure and policy decisions?

Three themes emerged from the data related to collaboration: improving services for EJ populations, enhanced understanding of other disciplines, and enhancing future research and planning.

\section{Improve services for EJ populations}

First, a transportation planner shared positive regard to interdisciplinary work, as it would improve services for clients served by social work, stating: “... I think it would be a good thing just simply because the more information you have the better decisions planners and engineers could make. There not like boots on the ground as we are or a social worker is with that population with those needs” (B). A professional in a social work-related field felt the same, addressing that it may be the only way to work towards improving services for persons in need, whereby she stated: "Well, I can certainly think that a collaboration is just going to be the only way that we can truly address these existing issues. If we continue to just work with our populations or just guess at what is needed then we're going to stay in this same place. We're going to have to, hopefully, work together. Whether that's on an individual relationship or actually systematically putting these relationships in place to be able to meet the needs of all the EJ populations and some are similar needs but some are different” (J). Finally, two social workers shared: "Well I think if they're gonna be putting forth services and designing services, you would think that they would want to be in contact with all the stakeholders, you know, everybody that's gonna be participating in that. To me, I guess, just being part of that discussion would be very helpful, 'cause you could provide information about a specific population in the community that could benefit from those services" (S), and that "Social service agencies all have to talk. The engineers don't know unless we tell them because we're the ones that are actually working with, and I say we even though it's not me, our agencies are the ones that are actually working with the clientele so there has to be communication to better the routes" (S). A focus group participant from the field of transporation planning endorsed these response from other professionals, where she stated: "I agree. Especially when you're creating on the ground projects. Sometimes what's drawn engineering-wise makes sense in that drawing phase, but then someone with a wheelchair coming through and trying to navigate certain things that have been previously designed, maybe they can't get around the bench and the light. You know, functionally, it looks great but then someone will navigate it. So it's getting those different perspectives from different parties that can really... Getting everyone's input can create a better project so it's not having to be done twice or going back through a couple of rounds” $(\mathrm{H})$.

\section{Enhanced understanding of other disciplines}


Across focus group participants, the concept of interdisciplinary collaborations was identified as an area that wold be positive and beneficial. Two social work participants reported: "I think part of the big reason why collaboration would be so beneficial is because the reputation, maybe a well-deserved reputation, that so many of the decisions that are made, are made kind of in a silo, right? So, not only do you have transportation engineers, and transportation planners, who might go about their work with a siloed approach to goals and outcomes. You also have that silo existing between transportation decision making and land use decision making. So, I'm not sure when you're using planning, if you're meaning transportation planning, or land use planning. But I would say that's also looked at as a separate discipline, when in fact they're very much directly tied together" (N). Additionally, "I think it's a great idea for all of these multidisciplinary professions to come together because each one of us carry different experiences in working with the community, and so when we're able to come together and share those experiences I think that we can brainstorm, and it will definitely help us fill the gap in whatever services the community might need” (L).

\section{Enhancing future research and planning}

The final theme from research question four identified that such interdisciplinary collaborations would enhance future research and planning efforts. One transportation planner stated: "I think also it can help make people feel a little more passionate about solving the problem. I think if you can put a human face on the problem, maybe people will be more interested in solving it" (K). Another participant, a civil engineer, shared: "So I think the channel to work with the other people, channel to connect to other people is really important, especially for this EJ population problem, but it's not easily accessible, especially for engineers because we are just dealing with the data in front of the computer” (K). Social workers agreed, whereby one participant shared: “...the "ah-ha" moments that we all have when we come together to discuss a beyond the issues of engineers and planners to implement and make things work in a way that is sustainable and then the "ah-ha" moments from their perspective on the needs and the circumstances and the situations that people who have transportation issues for whatever reason experience and the growth from those "ah-ha" moments is what continues to improve services and availability for people to live the lives they were intended to live with as few barriers as possible" (N).

These interdisciplinary efforts enhanced the experience of employees addressing needs of the community members through their research. One planner shared, "Yeah, some of the new technologies we're finding that will help protect our service areas are exciting. Some of them are more high concept, but being able to get the perspective helps us all realize, "Okay, yeah, that app is neat but here's a chunk of the population that's not gonna be served by it the way you think it's gonna be served by it." We try within our organization to be very interdisciplinary. We have a lot of different perspectives, just internally. Every now and then we're planning about something and get excited about something and you get that outside perspective. And that spirit of collaboration really helps us take care of those essential issues before something gets planned and solidified...it's very beneficial to have collaboration" (J). Another planner agreed, where she said: "I think it just basically helps us move ... There are two sides, I think, to the transportation solution or the transportation issue. One side has to do with the technical, are the roads gonna be built right? Are they going to be, or the public transit systems going to be functioning and cover certain areas? I think it leaves out the whole other side of how are people gonna interact with it” (J). 
These collaborations were noted to help with advocacy efforts and addressing current issues. One social work-related participant stated: "Well, I can certainly think that a collaboration is just going to be the only way that we can truly address these existing issues. If we continue to just work with our populations or just guess at what is needed then we're going to stay in this same place. We're going to have to, hopefully, work together. Whether that's on an individual relationship or actually systematically putting these relationships in place to be able to meet the needs of all the EJ populations and some are similar needs but some are different. Everybody really has point out, whether it's survivors of domestic violence or health care populations, they have similar needs, but then they also have very different factors that are important to them in accessing transit. The only way that we can address this, I think, is for all of us to start really working better together" (J). Finally a transportation planner shared, "I would advocate that it needs to be much more broad than social workers, planners, and engineers....You need to tie the economists in, the rail development, and some of the land value increases that are occurring...collaboration across economics, politics, schools, housing” (T).

\subsection{QUANTITATIVE RESULTS}

The survey explored the current relationships and interactions between transportation experts (i.e., civil engineers and transportation planners) and social workers to develop transportation solutions. In each research question category, multiple sub-questions were asked to collect indepth knowledge on current collaboration, available tools, and access to transportation systems.

Research Question 1: What skills/knowledge regarding transportation systems and users do engineers, planners, and social workers require in their profession?

The respondents first answered if they think transportation systems meet the needs of diverse populations, particularly individuals who are lower-income, older, or disabled. As shown in Table 3.1.2.1, transportation systems are considered to meet the needs of EJ communities to a small (40\%) or some (29\%) extent by social workers while transportation experts thought the needs meet to a moderate (31\%) or some (31\%) extent. Note that "others" in this analysis include counselor, client advocate, library programmer, mental health professional, non-profit administrator, nurse, professor, researcher and construction project manager.

Table 3.1.2.1: Experts' Opinions Regarding Whether Transportation Systems Meet the Needs of EJ Populations

\begin{tabular}{lccc}
\hline RESPONSES & $\begin{array}{c}\text { SOCIAL WORKER } \\
(\%) \\
(\mathrm{n}=96)\end{array}$ & $\begin{array}{c}\text { TRANSPORTATION } \\
\text { EXPERTS }(\%) \\
(\mathrm{n}=16)\end{array}$ & $\begin{array}{c}\text { OTHER (\%) } \\
(\mathrm{n}=14)\end{array}$ \\
\hline To a great extent & 6.3 & 12.5 & 7.1 \\
\hline To a very great extent & 5.2 & 12.5 & 14.3 \\
\hline To a moderate extent & 14.6 & 31.3 & 0 \\
\hline To some extent & 29.2 & 31.3 & 42.9 \\
\hline To a small extent & 40.6 & 12.5 & 28.6 \\
\hline Not at all & 4.2 & 0 & 7.1 \\
\hline
\end{tabular}

Table 3.1.2.2 shows the summarized results of important knowledge and skills related to transportation. Different knowledge was selected by professions. Available resources, 
transportation infrastructure or policy, and information on disadvantaged or at-risk populations were identified as the most important knowledge for social workers, transportation experts, and others, respectively (Table 3.1.2.2a). As the most important skills, advocacy was chosen by social workers while data analysis and public engagement were selected by transportation experts and others (Table 3.1.2.2b). In addition, research design (transportation planners), resource identification and provision for self-education (social workers) were specified as the important transportation-related skills.

Table 3.1.2.2: Transportation-Related Knowledge (a) and Skills (b)

\begin{tabular}{|c|c|c|c|}
\hline $\begin{array}{l}\text { (a) TRANSPORTATION-RELATED } \\
\text { KNOWLEDGE }\end{array}$ & $\begin{array}{c}\text { SOCIAL } \\
\text { WORKERS } \\
(\%)(n=207)\end{array}$ & $\begin{array}{c}\text { TRANSPORTATION } \\
\text { EXPERTS (\%) } \\
(\mathrm{n}=36)\end{array}$ & $\begin{array}{l}\text { OTHERS (\%) } \\
(\mathrm{n}=33)\end{array}$ \\
\hline Transportation infrastructure or policy & 18.8 & 41.7 & 33.3 \\
\hline $\begin{array}{l}\text { Available resources (e.g., discount fares, } \\
\text { transit assistance) }\end{array}$ & 42.5 & 30.6 & 30.3 \\
\hline $\begin{array}{l}\text { Disadvantaged, at-risk populations in need of } \\
\text { transportation }\end{array}$ & 38.6 & 27.8 & 36.4 \\
\hline Total & 100 & 100 & 100 \\
\hline $\begin{array}{l}\text { (b) TRANSPORTATION-RELATED } \\
\text { SKILLS }\end{array}$ & $\begin{array}{c}\text { SOCIAL } \\
\text { WORKERS } \\
(\%)(n=276)\end{array}$ & $\begin{array}{l}\text { TRANSPORTATION } \\
\text { EXPERTS }(\%)(\mathrm{n}=54)\end{array}$ & $\begin{array}{c}\text { OTHERS (\%) } \\
(\mathrm{n}=37)\end{array}$ \\
\hline Data analysis & 13.4 & 25.9 & 21.6 \\
\hline Advocacy & 28.6 & 18.5 & 24.3 \\
\hline Brokering services & 20.7 & 16.7 & 8.1 \\
\hline Engaging with the public & 25 & 22.2 & 32.4 \\
\hline Writing policies & 12.3 & 16.7 & 13.5 \\
\hline Total & 100 & 100 & 100 \\
\hline
\end{tabular}

Respondents answered to what extent the three different professions of social work, civil engineering, and transportation planning can inform transportation system planning (Table 3.1.2.3). Many of the professionals (70\% of social workers, $53 \%$ of transportation experts and $76 \%$ of others) reported that all the disciplines can inform transportation system planning to a great or a very great extent.

Table 3.1.2.3: Professions Informing Transportation System Planning

\begin{tabular}{|c|c|c|c|c|}
\hline \multirow{7}{*}{$\begin{array}{l}\text { SOCIAL SERVICE } \\
\text { PROVIDERS } \\
\text { INFORM } \\
\text { TRANSPORTATION } \\
\text { PLANNING }\end{array}$} & Response Options & $\begin{array}{l}\text { Social } \\
\text { Workers (\%) } \\
(n=94)\end{array}$ & $\begin{array}{l}\text { Transportation } \\
\text { Experts (\%) } \\
(n=15)\end{array}$ & $\begin{array}{l}\text { Others }(\%) \\
(n=13)\end{array}$ \\
\hline & To a great extent & 25.5 & 40 & 30.8 \\
\hline & $\begin{array}{l}\text { To a very great } \\
\text { extent }\end{array}$ & 45.7 & 13.3 & 46.2 \\
\hline & $\begin{array}{l}\text { To a moderate } \\
\text { extent }\end{array}$ & 12.8 & 26.7 & 15.4 \\
\hline & To some extent & 6.4 & 20 & 7.7 \\
\hline & To a small extent & 5.3 & 0 & 0 \\
\hline & Not at all & 4.3 & 0 & 0 \\
\hline
\end{tabular}




\begin{tabular}{|c|c|c|c|c|}
\hline Total & & 100 & 100 & 100 \\
\hline \multirow{7}{*}{$\begin{array}{l}\text { CIVIL ENGINEERS } \\
\text { INFORM } \\
\text { TRANSPORTATION } \\
\text { PLANNING }\end{array}$} & Response Options & $\begin{array}{l}\text { Social } \\
\text { Workers (\%) } \\
(n=91)\end{array}$ & $\begin{array}{l}\text { Transportation } \\
\text { Experts (\%) } \\
(n=16)\end{array}$ & $\begin{array}{l}\text { Others (\%) } \\
(n=14)\end{array}$ \\
\hline & To a great extent & 28.6 & 37.5 & 28.6 \\
\hline & $\begin{array}{l}\text { To a very great } \\
\text { extent }\end{array}$ & 52.7 & 31.3 & 64.3 \\
\hline & $\begin{array}{l}\text { To a moderate } \\
\text { extent }\end{array}$ & 12.1 & 25 & 7.1 \\
\hline & To some extent & 3.3 & 0 & 0 \\
\hline & To a small extent & 1.1 & 6.3 & 0 \\
\hline & Not at all & 2.2 & 0 & 0 \\
\hline Total & & 100 & 100 & 100 \\
\hline \multirow{7}{*}{$\begin{array}{l}\text { TRANSPORTATION } \\
\text { PLANNERS } \\
\text { INFORM } \\
\text { TRANSPORTATION } \\
\text { PLANNING }\end{array}$} & Response Options & $\begin{array}{l}\text { Social } \\
\text { Workers (\%) } \\
(n=91)\end{array}$ & $\begin{array}{l}\text { Transportation } \\
\text { Experts (\%) } \\
(n=15)\end{array}$ & $\begin{array}{l}\text { Others (\%) } \\
(n=14)\end{array}$ \\
\hline & To a great extent & 27.5 & 13.3 & 28.6 \\
\hline & $\begin{array}{l}\text { To a very great } \\
\text { extent }\end{array}$ & 68.1 & 73.3 & 71.4 \\
\hline & $\begin{array}{l}\text { To a moderate } \\
\text { extent }\end{array}$ & 2.2 & 6.7 & 0 \\
\hline & To some extent & 1.1 & 6.7 & 0 \\
\hline & To a small extent & 0 & 0 & 0 \\
\hline & Not at all & 1.1 & 0 & 0 \\
\hline \multicolumn{2}{|l|}{ Total } & 100 & 100 & 100 \\
\hline
\end{tabular}

Lastly, the research team identified five strategies (community engagement, data collection, advocacy efforts, developing comprehensive performance measures and implementing comprehensive performance measures) that are critically used for improving transportation planning. Respondents ranked the strategies from most important (ranked \#1) to least important (ranked \#5) for transportation planning, as shown in Table 3.1.2.4. Community engagement, data collection, and advocacy efforts were the top three strategies that social workers consider to be important for improving transportation planning while data collection, developing comprehensive performance measures, and community engagement were identified as the most important three strategies for transportation experts.

Table 3.1.2.4: Strategies for Improving Transportation Planning

\begin{tabular}{cll}
\hline RANKING & \multicolumn{1}{c}{ SOCIAL WORKERS } & \multicolumn{1}{c}{ TRANSPORTATION EXPERTS } \\
\hline 1 & Community Engagement (44.2\%) & Data Collection (43.8\%) \\
\hline 2 & Data Collection (36.4\%) & $\begin{array}{l}\text { Developing Comprehensive Performance } \\
\text { Measures (PMs) (31.3\%) }\end{array}$ \\
\hline 3 & Advocacy Efforts (13\%) & Community Engagement (25\%) \\
\hline 4 & Implementing Comprehensive PMs (3.9\%) & Implementing Comprehensive PMs (<1\%) \\
\hline 5 & Developing Comprehensive PMs (2.6\%) & Advocacy Efforts (<1\%) \\
\hline
\end{tabular}


Research Question 2: To what extent do engineers, planners, and social workers interact regarding transportation infrastructure and policy?

The respondents were first asked about how frequently each professional works with other disciplines/professions (transportation experts and social workers) to improve transportation infrastructure and policy. Interestingly, the results indicate that $78 \%$ of social workers and $41 \%$ of transportation experts never work with transportation experts and social workers, respectively.

Table 3.1.2.5: Interactions Between Social Workers with Other Professions

\begin{tabular}{cccccc}
\hline & Daily & Weekly & Monthly & Bi-annually & Never \\
\hline Transportation Experts & 0 & 0 & $1.6 \%$ & $6.6 \%$ & $78.4 \%$ \\
\hline Social Workers & $28.6 \%$ & $7.7 \%$ & $5.5 \%$ & $3.3 \%$ & $18.7 \%$ \\
\hline
\end{tabular}

Table 3.1.2.6: Interactions Between Transportation Experts (Civil Engineers/Transportation Planners) with Other Disciplines

\begin{tabular}{clllll}
\hline & Daily & Weekly & Monthly & Bi-annually & Never \\
\hline Transportation Experts & $22.3 \%$ & $10 \%$ & $19.2 \%$ & $12.9 \%$ & $12.9 \%$ \\
\hline Social Workers & 0 & $5.9 \%$ & $23.5 \%$ & $11.8 \%$ & $41.2 \%$ \\
\hline
\end{tabular}

However, both social workers (62\%) and transportation experts (76\%) reported that working with other professions is very or extremely important to improve transportation infrastructure and policy. The professionals use workshops, local/state/national conferences, and public hearing to meet and interact with other professionals. In addition, the respondents reported local meetings, collaboration for projects or research, field work, phone call/emails/referrals as potential interaction opportunities with other professionals.

Table 3.1.2.7: Importance of Interdisciplinary Collaboration

\begin{tabular}{cccc}
\hline RESPONSE OPTIONS & $\begin{array}{c}\text { Social Workers (\%) } \\
(\mathrm{n}=96)\end{array}$ & $\begin{array}{c}\text { Transportation } \\
\text { Experts (\%) }(\mathrm{n}=30)\end{array}$ & $\begin{array}{c}\text { Others (\%) } \\
(\mathrm{n}=14)\end{array}$ \\
\hline Extremely important & 34.4 & 30 & 35.7 \\
\hline Very important & 28.1 & 46.7 & 35.7 \\
\hline Moderately important & 16.7 & 13.3 & 7.1 \\
\hline Slightly important & 15.6 & 6.7 & 14.3 \\
\hline Not at all important & 5.2 & 3.3 & 7.1 \\
\hline Total & 100 & 100 & 100 \\
\hline
\end{tabular}

Table 3.1.2.8: Context of Professional Interactions

\begin{tabular}{cccc}
\hline RESPONSE OPTIONS & $\begin{array}{c}\text { Social Workers (\%) } \\
(\mathrm{n}=215)\end{array}$ & $\begin{array}{c}\text { Transportation } \\
\text { Experts (\%) }(\mathrm{n}=49)\end{array}$ & $\begin{array}{c}\text { Others (\%) } \\
(\mathrm{n}=27)\end{array}$ \\
\hline Workshops & 20 & 14.3 & 7.4 \\
\hline State Conferences & 13.5 & 8.2 & 14.8 \\
\hline Public Hearing Meeting & 7.0 & 20.4 & 7.4 \\
\hline Local Conferences & 24.7 & 20.4 & 22.2 \\
\hline National Conferences & 8.8 & 10.2 & 3.7 \\
\hline Forums & 11.2 & 14.3 & 11.1 \\
\hline
\end{tabular}




\begin{tabular}{cccc}
\hline City Council & 2.8 & 4.1 & 11.1 \\
\hline $\begin{array}{c}\text { Not Applicable - (do not work with other } \\
\text { professions) }\end{array}$ & 8.8 & 6.1 & 3.7 \\
\hline Other & 3.3 & 2.0 & 18.5 \\
\hline Total & 100 & 100 & 100 \\
\hline
\end{tabular}

Research Question 4: What benefits do professionals see for engineers, planners, and social workers to interact when making transportation infrastructure and policy decisions?

The last research question captured the benefits of different professions' interaction when making transportation infrastructure and policy decisions. First, the respondents positively considered the interdisciplinary interaction (94\% of social workers, $100 \%$ of transportation experts, and $84 \%$ of others). The most preferred platforms for the interaction/meetings was "both in-person and online" (62\%), followed by "in-person interprofessional meeting” (24\%), and online/virtual conference platform (14\%).

The research team identified seven transportation infrastructure and policy decisions (Table 2.2) and asked respondents how helpful the interdisciplinary collaborations would be for each decision. The respondents answered the question with five degrees of importance (extremely helpful $=5$, very helpful $=4$, somewhat helpful $=3$, slightly helpful=2 and not at all helpful=1). Similar to the analysis used for Table 8, the scores for each decision were combined and ranked by professions. Results showed that the top decisions that the interdisciplinary collaboration would be helpful is "To improve transportation for the overall community" (social workers and others), and "To expand each profession's understanding of transportation planning within the community" (transportation experts).

Table 3.1.2.9: Transportation Infrastructure and Policy Decisions with Interdisciplinary Collaboration

\begin{tabular}{lccc}
\hline \multicolumn{1}{c}{ RESPONSES } & \multicolumn{2}{c}{ RANKING } \\
\cline { 2 - 4 } & $\begin{array}{c}\text { Social } \\
\text { Workers }\end{array}$ & $\begin{array}{c}\text { Transportation } \\
\text { Engineers }\end{array}$ & Others \\
\hline To improve transportation for the overall community & 1 & 3 & 1 \\
\hline For social workers to communicate with transportation engineers/planners & 2 & 2 & 2 \\
\hline $\begin{array}{l}\text { To expand each professions' understanding of transportation planning } \\
\text { within the community }\end{array}$ & 3 & 6 & 5 \\
\hline For engineers/planners to communicate with social workers & 4 & 5 & 3 \\
\hline For the reputability and rigor of future research efforts & 5 & 6 & 4 \\
\hline To improve overall services for EJ population & 6 & 6 \\
\hline
\end{tabular}

A question was asked to evaluate benefits of an interdisciplinary undergraduate or graduate studies. The respondents answered how beneficial they think an interdisciplinary course related to transportation in their undergraduate or graduate studies would have been for their current work. A total of $35.1 \%$ social workers believe that transportation-related interdisciplinary courses are somewhat beneficial, and 31.1\% of social workers believe that the transportationrelated interdisciplinary course would is very helpful for their current work. The majority of 
transportation experts (87.5\%) also positively evaluated their interdisciplinary courses while $54.5 \%$ of other professionals reported the course would have been helpful.

In addition, different interdisciplinary courses that might have been useful for undergraduate and graduate studies were asked about, as shown in Table 3.2.2.1.2. The results show that the transportation experts tend to positively evaluate the interdisciplinary courses more than social workers. For example, 71\% social workers thought interdisciplinary courses with transportation planners might have been useful for their undergraduate and graduate studies, while $82 \%$ of transportation experts that courses with social workers might have been useful for their profession.

Table 3.1.2.10: Interdisciplinary Courses that Might have been Useful for Undergraduate and Graduate Studies

\begin{tabular}{cccc}
\hline & \multicolumn{3}{c}{ RESPONDENTS' PROFESSIONS } \\
\hline Interdisciplinary courses with... & $\begin{array}{c}\text { Social Workers } \\
(\mathrm{n})\end{array}$ & $\begin{array}{c}\text { Transportation Experts } \\
(\mathrm{n})\end{array}$ & Others (n) \\
\hline Social Workers & $42 \%$ of $(\mathrm{n}=149)$ & $82 \%$ of $(\mathrm{n}=11)$ & $87.5 \%$ of $(\mathrm{n}=8)$ \\
\hline Transportation Planners & $71 \%$ of $(\mathrm{n}=84)$ & $100 \%$ of $(\mathrm{n}=13)$ & $80 \%$ of $(\mathrm{n}=10)$ \\
\hline Civil Engineers & $58 \%$ of $(\mathrm{n}=84)$ & $100 \%$ of $(\mathrm{n}=12)$ & $82 \%$ of $(\mathrm{n}=11)$ \\
\hline Computer Science & $67 \%$ of $(\mathrm{n}=84)$ & $100 \%$ of $(\mathrm{n}=11)$ & $64 \%$ of $(\mathrm{n}=11)$ \\
\hline City/Regional Planners & $84 \%$ of $(\mathrm{n}=85)$ & $100 \%$ of $(\mathrm{n}=13)$ & $80 \%$ of $(\mathrm{n}=10)$ \\
\hline Urban Design & $86 \%$ of $(\mathrm{n}=87)$ & $92 \%$ of $(\mathrm{n}=13)$ & $80 \%$ of $(\mathrm{n}=10)$ \\
\hline
\end{tabular}

Lastly, the respondents indicated other interdisciplinary options that were available for them in undergraduate or graduate education. The results showed that a wide variety of options were available to the professionals including workshops, special lectures, research activities, and internships for both social workers and transportation experts. In addition, dual program studies such as a dual degree in social work and law or a dual degree in social work and public health are selected as the potential interdisciplinary options.

Table 3.1.2.11: Interdisciplinary Options in Undergraduate or Graduate Education

\begin{tabular}{cccc}
\hline Interdisciplinary Options & $\begin{array}{c}\text { Social Workers (\%) } \\
(\mathrm{n}=251)\end{array}$ & $\begin{array}{c}\text { Transportation Experts } \\
(\%)(\mathrm{n}=34)\end{array}$ & $\begin{array}{c}\text { Others (\%) } \\
(\mathrm{n}=26)\end{array}$ \\
\hline Workshops & 17.9 & 23.5 & 19.2 \\
\hline Special Lectures & 18.7 & 23.5 & 23.1 \\
\hline Research Activities & 19.9 & 26.5 & 19.2 \\
\hline Independent Studies & 13.1 & 8.8 & 19.2 \\
\hline $\begin{array}{c}\text { Internship/Field } \\
\text { Placement/Practicum }\end{array}$ & 28.3 & 14.7 & 7.7 \\
\hline Other & 2.0 & 2.9 & \\
\hline
\end{tabular}




\subsubsection{User Feedback on Utilizing Mobile Device Apps}

Lastly, this study explored, in research question three, the feasibility of using features of twomobile device applications on job effectiveness. This research question asked: To what extent could engineers, planners, and social workers utilize the data and features within Safe Activity and My Amble to accomplish their jobs more effectively?

\subsection{QUALITATIVE RESULTS}

Two themes emerged from the data related to the data and features within the apps: collecting longitudinal data and crowd-sourced/real-time data. All three disciplines identified the utility of these features.

\section{Collecting longitudinal data}

The first theme that emerged was collecting longitudinal data. One social work participant stated, "It still has been one of the major barriers to getting the data, getting the follow up data, getting 12 month follow ups. We've sort of been jumping through hoops to try to get data from patients that have been out of treatment for six months or whatever it is" (C). Another social worker who works directly with families said the same thing, sharing: "As for our families who're trying to change how we provide services for our families, particularly ones in our suburban areas, that would be good data to have in order to support our claim that this is not just an isolated example or situation with one particularly unique family, but that this is a pattern and a lot of our funding sources have to have supporting data to fund such changes. Tracking that for a six-month period of time or something like that, that would help support our request when we have a new fiscal budgeting year coming up, we can support that” (R).

\section{Crowd-sourced and real-time data}

The final theme that emerged from partiicpants is that they can benefit from the use of crowd-sourced and real-time data. One participant, a civil engineer stated: "I think a good way to use as far as to collect data or to be used in the planning process, the traditional way of doing this is using diaries or something where people write down where they're going, how long it takes to get there, and so forth, and which mode they take. Somehow this could be used to look at what they're doing, what the communities doing, but also...the suppressed travels, travels they can't make. I think that should be an important input into this which I don't think we're getting now" (J). A social worker, also made a nod to the benefits and positive outcome these features would have on their practice, "From my perspective, I think that would be fantastic. Especially for us, when we do get phone calls from communities that don't have public transportation and if they had or we had access to that data, it would certainly help us in planning whether or not they need demand-response transportation or if they need a fixed route. The data we have is more census data rather than actual hardcore transportation data" (K). Another social worker said, "I mean I think it would be definitely helpful, just on the level of being able to collect the data to help make your point. We can explain the stories on behalf of the residents all day long, but having it be in their own words and have it be like their factual information and being able to take it to somebody and be like, "Look, this is why this matters," or, "This is why we need this grant money," or ... I mean, I think it's invaluable in any way, in order to either get more services done or to receive funds to create something on our own” $(\mathrm{H})$. 
Another social worker stated that this can be helpful, from her professional perspective and skillset, whereby she said, "I think a lot of social service providers can name a lot of the challenges and certainly a lot of populations can name a lot of the challenges that they're facing, but it's about how do we collect it systematically and collate it in a way that other people who are making broader systems decisions can use and be informed by the perspectives of these different EJ populations. A group of survivors of domestic violence might have a broad range of fairly similar experiences and a domestic violence service provider might not be very surprised by what the data's say but the ability to collate it and package it in a way that can be useful then to systems planners, I think is the piece that's, could be really, really helpful, from a social systems, social services perspective" (R). Similarly, a transportation planner said, "Because when you're hearing people, if they're particularly trying to get to work or to get to a specific location, you can focus those efforts and look towards creating a solution for getting to work for that particular node. But as well, it can also lead or identify different types of funding that could be used. FTA, particularly, has specific types of funds for older adults, people with disabilities, for accessing work and jobs. I know there are probably other sources of funds, particularly for other populations, but those pieces of information can really help pull together a solution” $(\mathrm{H})$.

Another participant, a civil engineer, said that “... a tool like this would definitely be useful because you have a platform that allows you to be flexible with your questioning and probably ... you can kind of tailor the questions to what you're trying to find out about their situation and make it relevant to the planning process or the engineering process ... it would definitely be useful in that regard, and it would probably play a good role for us as planners in like a validation role, so how do we validate our plans and the part of the modeling that we do and when we try to incorporate these populations" (C). Lastly, two social workers identified that this real-time, innovative data collection method could be valuable, sharing, "I think the capturing of that kind of data on a ... I don't know the right word, but as it happens rather than talking to people later about, "What kind of transportation needs did you have last month?" You know? I don't think you would get as accurate that way as you would on a daily basis. I think ... Especially people who have never driven, who have disabilities and have never really had the freedom of deciding, "Oh, I want to go to Walmart. Think I'll go get in my car and drive there." To give them the opportunity to look at their daily life and, you know, capture what they would've done or would have liked to have done but couldn't would be valuable” $(\mathrm{N})$, and that one agency even discussed this, sharing: "We've talked about just doing paper surveys with a lot more participants to try and get at the same type of questions. Something that's a little more real time like an app that could add just another depth to the data” (J).

\subsection{QUANTITATIVE RESULTS}

The third research question asked about required features or utility as a function of an app when collecting transportation activity data using a mobile device app (e.g., Safe Activity and My Amble). The research team identified 12 features as shown in Table 3.2.2.9. The respondents evaluated each feature and indicated how much the feature would be helpful to collect transportation activity data. The respondents rated each feature (extremely helpful, very helpful, somewhat helpful, slightly helpful, and not at all helpful) to indicate the importance of the feature. 
The research team ranked the features by professions. The top three rated features selected by social workers are "open-ended question," "multilingual text," and "regional transportation information.” For the transportation experts, however, the features related to accurate data collection, such as "interactive map with GPS," "GPS pinpoint user locations," and "features that capture longitudinal data,” were chosen as the most important features.

Table 3.1.2.12: Ranking of Features for a Mobile Device App that Collects Transportation Activity Data

\begin{tabular}{|c|c|c|c|}
\hline \multirow[t]{2}{*}{ FEATURES } & \multicolumn{3}{|c|}{ RANKING } \\
\hline & $\begin{array}{c}\text { Social } \\
\text { Workers }\end{array}$ & $\begin{array}{l}\text { Transportation } \\
\text { Experts }\end{array}$ & Others \\
\hline Open-ended questions for users to provide responses of their choosing & 1 & 11 & 10 \\
\hline Multilingual text & 2 & 5 & 4 \\
\hline $\begin{array}{l}\text { Embedded regional transportation resources that users can search for and } \\
\text { utilize }\end{array}$ & 3 & 7 & 6 \\
\hline Interactive map with GPS & 4 & 1 & 1 \\
\hline GPS to pinpoint user location & 5 & 2 & 2 \\
\hline Questions about user's preferred transportation mode & 6 & 6 & 5 \\
\hline Questions about user's actual transportation mode & 7 & 4 & 3 \\
\hline Features that capture longitudinal data & 8 & 3 & 8 \\
\hline $\begin{array}{l}\text { Embedded national transportation resources that users can search for and } \\
\text { utilize }\end{array}$ & 9 & 10 & 9 \\
\hline $\begin{array}{l}\text { Asynchronous features, (i.e., users can utilize the app and answer } \\
\text { questions when they choose) }\end{array}$ & 10 & 8 & 7 \\
\hline Crowd-sourced data & 11 & 9 & 11 \\
\hline Interactive map without GPS & 12 & 12 & 12 \\
\hline
\end{tabular}




\subsection{CONCLUSION}

Transportation planning and engineering have traditionally struggled to serve at-risk communities and environmental justice (EJ) populations. Social workers often struggle to connect with the planners and engineers whose transportation designs impact the individuals and communities that utilize social services. Evidence of these struggles manifest as unequal transportation system outcomes related to access and opportunity, as well as in perceived mismatch between the needs of the community and transportation priorities. Adequately serving EJ populations requires re-evaluating long-held assumptions and practices within the transportation and social work professions, particularly with regard to the understanding of transportation gaps and needs of vulnerable populations. The aim of this project was to explore how engineers, planners, and social workers interact around issues of transportation and transportation equity and to identify opportunities for enhanced collaboration and educational training.

The study has notable strengths. First, the mixed-method design allowed us to both measure the degree to which professionals across disciplines recognize a need for interprofessional approaches to addressing transportation, as well as the quality of this recognition. The triangulated design allows us to make more specific recommendations about increasingly interprofessional transportation practices.

There were some limitations to the study results. First, despite intentional outreach across all three disciplines, respondents to the quantitative survey were overwhelmingly social workers. While the reasons for the response bias are uncertain, it may be due in part to the fact that the primary investigator and one of the co-investigators are social work academics who relied heavily on their social work networks in order to recruit respondents. We did make multiple attempts to reach out to social networks of transportation planners and engineers, but they may have been less familiar with the researchers, and thus, reluctant to respond.

Second, the uneven distribution of respondents in the survey made testing for group differences across the three professions unfeasible. We were able to describe the differences, however, and they did show divergent perspectives. These results point to the need for replicating the study with a more robust sampling strategy, which will allow us to determine if the differences are, in fact, statistically significant.

Finally, the disproportionately small numbers of transportation planning and engineering responses mean that these results may not be representative of these professions. Instead, results may reflect only those most motivated to engage in interprofessional practice, or those who are more geographically or personally proximal to the research team. 
A main focus of this study was related to whether current transportation systems promote transportation equity across communities, particularly for individuals who are at high risk of transportation disadvantage (i.e. EJ populations). The qualitative data suggests that improving services for EJ populations was important to both social workers and transportation planners. However, fewer social workers report that transportation systems meet the needs of EJ population members. The quantitative findings suggest that across all three professions, transportation systems only meet the needs of EJ communities to a small to moderate/some extent. Overall, participants across disciplines recognized the importance of addressing the unmet and/or underserved transportation needs of EJ populations. Given that research demonstrates that transportation disadvantage may have detrimental impacts on individuals' quality of life (20), employment (21), education (22), social activities (23), nutrition and health care (24), findings underscore the pressing need to increase efforts toward maximing transportation equity for EJ populations. Considering general disclination regarding mass transit, and the expense involved, policy implications might include legislative support to fund innovative, on-demand, and door-to-door services like ride-sharing and car-sharing programs. This could be accomplished by leveraging more public-private partnerships.

Secondly, the study examined the skills and knowledge regarding transportation systems and users that engineers, planners, and social workers required in their respective professions. The qualitative and quantitative data suggest that advocacy and resource identification were among some of the most important transportation-related skills needed for social workers while data analysis and planning were reported as key skills for transportation experts. Of interest is that the findings indicate that connecting with stakeholders and public engagement were important skills for both social workers and transportation experts. This overlap offers a promising avenue for interdisciplinary collaboration. Another area of overlap for interdisciplinary collaboration may be in writing/creating policy, as this was identified as an important knowledge/skill for all disciplines in the survey data. Previous research suggests that social workers and engineers are well-position to focus on community development, working toward addressing the complex needs of individuals, families, and communities (25). Thus, study findings support increased efforts toward creating synergy between disciplines and skill sets.

Third, the study explored the extent to which engineers, planners, and social workers interact regarding transportation infrastructure and policy. The majority of study participants indicated that all three disciplines can greatly inform transportation planning and that interdisciplinary collaboration is important for improving and enhancing transportation planning. These findings are consistent with previous research suggesting a resurgent interest in interdisciplinary work in social science and engineering (25). While the qualitative and quantitative findings suggest that the disciplines have some opportunities to interact (e.g., advisory councils, workshops, forums), the focus group participants in particular shared that these interactions are limited and "siloed." While respondents from different disciplines valued interprofessional collaboration, they rarely did so. Still, they spoke to the value of interprofessional practice for improving transportation services for EJ populations. As one person said, interprofessional practice can help us to address the technical side of transportation planning as well as the social - understanding how people are going to interact with the technical solutions. 
Fourth, the study examined the benefits that professionals see for engineers, planners, and social workers to interact when making transportation infrastructure and policy decisions. It is interesting that the survey results indicated that interdisciplinary collaborations might allow for social workers to better communicate with transportation engineers and planners. Given that many social service providers in the focus groups shared that they had little access to transportation engineers and planners, these findings bolster support for the value of interdisciplinary collaboration, particularly for social workers. Findings also underscore the desire for transportation engineers and planners to have opportunities to communicate with social workers.

Fifth, as a first step in exploring future interdisciplinary education strategies, participants were asked to evaluate benefits of an interdisciplinary undergraduate or graduate course related to transportation. Although transportation experts reported the most potential benefit, social workers responded that an interdisciplinary course would have been somewhat or very helpful. In particular, social workers expressed interest in interdisciplinary coursework with transportation planners. Transportation experts also reported that a course with social workers could have been useful for their professional training. Survey results indicated existing avenues for interdisciplinary coursework including workshops, research activities, and internships, which suggests that there are opportunities to build curriculum for social workers and transportation students. Given that study findings suggest that interdisciplinary collaboration is welcomed and needed among social workers and transportation experts, the academic departments of engineering, planning, and social work ought to consider design of graduate-level seminars on topics related to transportation co-led by the three disciplines and cross-listed. These might include perspectives of EJ populations, use of new technologies like autonomous vehicles and how public planning and issues like zoning laws influence transportation infrastructure and resources. Such seminars could include capstone, service-learning or experiential projects that allow the students to apply their skills to real-world transportation issues in interdisciplinary teams.

Finally, the study examined the utility of two new digital data collection tools, MyAmble and Safe Activity. Previous research suggests that digitial platforms offering new ways to collect holistic data related to transportation and transportation disadvantage may lead to better opportunities for social workers, engineers, and transportation planners to work together to address the needs of EJ populations (26). Participants in the focus groups reported utility in collecting longitudinal, crowd-sourced/real-time data with the MyAmble and Safe Activity apps. The survey data provided a more detailed examination of which features of the app were most useful to each discipline. Consistent with other results, when respondents were asked about utilizing smart technologies and apps in transportation planning, the social workers cited the utility of gathering narrative data, while the engineers and planned identified more quantitative data features such as GPS and pinpointing user locations and travel activities. Although each discipline differed in what was deemed as most useful, findings suggest overall that MyAmble and Safe Activity offer promise in collecting meaningful data for both social workers and transportation experts. Furthermore, MyAmble and Safe Activity may provide an innovative data collection platform to encourage interdisciplinary collaboration among social workers and transportation experts. 


\subsection{REFERENCES}

1. Gilbert, D. J. (2014). Social work and engineering collaboration: Forging innovative global community development education. Journal of Social Work Education, 50(2), 292-304.

2. Frickel, S., Peterson, S., Albert, M., Prainsack, B., Nowotny, H., McBee, D., Leahey, E., Downey, G.J., Feinstein, N.W., \& Kleinman, D.L. (2016). Investigating interdisciplinary collaboration: Theory and practice across disciplines. New Brunswick, N.J.: Rutgers University Press.

3. Harvard School of Public Health. (n.d.). Definitions, Harvard Transdisciplinary Research in Energetics and Cancer Center. Retrieved from: https://www.hsph.harvard.edu/trec/aboutus/definitions/

4. Stock, P., \& Burton, R. J. (2011). Defining terms for integrated (multi-inter-transdisciplinary) sustainability research. Sustainability, 3(8), 1090-1113.

5. Miller, V.J., Murphy, E.R., Cronley, C., Fields, N., \& Keaton, C. (In press). Student experiences of engaging in interdisciplinary research collaborations: A case study for social work education. Journal of Social Work Education.

6. Aboelela, S. W., Larson, E., Bakken, S., Carrasquillo, O., Formicola, A., Glied, S. A., ... Gebbie, K. M. (2007). Defining interdisciplinary research: Conclusions from a critical review of the literature. Health Services Research, 42, 329-346. doi: 10.1111/j.14756773.2006.00621.x

7. World Health Organization [WHO] (2007). Ageing and life course: Towards an age- friendly world. Retrieved from http://www.who.int/ageing/age-friendly- world/en/

8. U. S. Government Accountability Office (2004). Transportation disadvantaged seniors efforts to enhance senior mobility could benefit from additional guidance and information. 
Report to the Chairman, Special Committee on Ageing, U.S. Senate. Washington, D.C.: Report GAO-04-971. Retrieved from http:/www.gao.gov/products/GAO-04-971

9. Miller, V.J., Murphy, E.R., Cronley, C., Fields, N.L., \& Keaton, C. (In press). Student experiences engaging in interdisciplinary research collaborations: A case study for social work education. Journal of Social Work Education.

10. Mack, J. (2016). Social exclusion. Retrieved from http://www.poverty.ac.uk/definitionspoverty/social-exclusion

11. Creswell, J. W., Plano Clark, V. L., Gutmann, M. L., \& Hanson, W. E. (2003). Advanced mixed methods research designs. In A. Tashakkori \& C. Teddlie (Eds.), Handbook of mixed methods in social and behavioral research (pp. 209-240). Thousand Oaks, CA: Sage.

12. Krueger, R.A \& Casey, M.A. (2000). Focus Groups: A Practical Guide for Applied Research. Thousand Oaks, CA: Sage.

13. Carlsen, B. \& Glenton, C. (2011). What about N? A methodological study of sample-size reporting in focus group studies. BMC Medical Research Methodology, 11(1)26.

14. Hsieh, H. F., \& Shannon, S. E. (2005). Three approaches to qualitative content analysis. Qualitative Health Research, 15(9), 1277-1288.

15. Given, L. M. (2008). The SAGE encyclopedia of qualitative research methods (Vols. 1-0). Thousand Oaks, CA: SAGE Publications, Inc. doi: 10.4135/9781412963909

16. Van Horn, P. S., Green, K. E., \& Martinussen, M. (2009). Survey response rates and survey administration in counseling and clinical psychology: A meta-analysis. Educational and Psychological Measurement, 69(3), 389-403.

17. Cohen, J. (1992). A power primer. Quantitative methods in psychology, 112(1), 155-159. 
18. Potter, W. J., \& Levine-Donnerstein, D. (1999). Rethinking validity and reliability in content analysis. Journal of Applied Communication Research, 27, 258-284.

19. Hickey, G., \& Kipping, C. (1996). Issues in research. A multi-stage approach to the coding of data from open-ended questions. Nurse Researcher, 4, 81-91.

20. Adorno, G., Fields, N., Cronley, C., Parekh, R., and Magruder, K. (2018). Ageing in a LowDensity Urban City: Transportation Mobility as a Social Equity Issue. Ageing and Society, 38(2), 296- 320.

21. Li, H., Raeside, R., Chen, T., \& McQuaid, R. W. (2012). Population ageing, gender and the transportation system. Research in Transportation Economics, 34(1), 39-47.

22. Sanchez, T. W., Stolz, R., and Ma, J. S. Moving to Equity: Addressing Inequitable Effects of Transportation Policies on Minorities. The Civil Rights Project at Harvard University, Cambridge, Massachusetts, 2003.

23. Currie, G., Richardson, T., Smyth, P., Vella-Brodrick, D., Hine, J., Lucas, K., Stanley, J., Morris, J., Kinnear, R., and Stanley, J. (2009). Investigating Links between Transport Disadvantage, Social Exclusion and Well-Being in Melbourne - Preliminary results. Transport Policy,16(3), pp. 97-105.

24. Shay, E., Combs, T. S., Findley, D., Kolosna, C., Madeley, M., and Salvesen, D. (2016). Identifying transportation disadvantage: Mixed-methods analysis combining GIS mapping with qualitative data. Transport Policy, 48, 129-138.

25. Gilbert, D. J. (2014). Social work and engineering collaboration: forging innovative global community development education. Journal of Social Work Education, 50(2), 292-304.

26. Fields, N.L., Cronley, C., Mattingly, S., Murphy, E., \& Miller, V.J. (in press). "You are really at their mercy”: Examining the relationship between transportation disadvantage and 
social exclusion among older adults through the use of innovative technology.

Transportation Research Board. 


\subsection{APPENDICES}

\section{APPENDIX A}

\begin{tabular}{c|l} 
University of & OFFICE OF RESEARCh ADMINISTRATION \\
TEXXAS & REgULATORY SERVICES
\end{tabular}

Institutional Review Board

Notification of Exemption - Federally Funded Study

March 28, 2018

Dr. Noelle Fields

School of Social Work

The University of Texas at Arlington

Box 19129

Protocol Number: 2018-0470

Protocol Title: How can interdisciplinary teams leverage emerging technologies to respond to transportation infrastructure needs? A mixed-methods evaluation of civil engineers, urban

planning, and social workers' perspectives

Study Sponsor: Portland State University

Federal Funding Source (Prime Sponsor): US Department of Transportation (DOT)

Award Number: NITC2016-UT-07

Mentis Bluesheet Number: 2017-609-S6

\section{EXEMPTION DETERMINATION}

The UT Arlington Institutional Review Board (IRB) Chair, or designee, has reviewed the above referenced study and found that it qualified for exemption under the federal guidelines for the protection of human subjects as referenced at Title 45CFR Part 46.101(b)(2).

- (2) Research involving the use of educational tests (cognitive, diagnostic, aptitude, achievement), survey procedures, interview procedures or observation of public behavior, unless:(i) information obtained is recorded in such a manner that human subjects can be identified, either directly or through identifiers linked to the subject; and (ii) any disclosure of the human subjects' responses outside the research could reasonably place the subjects at risk of criminal or civil liability or be damaging to the subjects' financial standing, employability, or reputation.

You are therefore authorized to begin the research as of March 28, 2018.

Pursuant to Title 45 CFR 46.103(b)(4)(iii), investigators are required to, "promptly report to the IRB any proposed changes in the research activity, and to ensure that such changes in approved research, during the period for which IRB approval has already been given, are not initiated without prior IRB review and approval except when necessary to eliminate apparent immediate hazards to the subject." All proposed changes to the research must be submitted via the electronic submission system prior to implementation. Please also be advised that as the principal investigator, you are required to report local adverse (unanticipated) events to the Office of Research Administration; Regulatory Services within 24 hours of the occurrence or upon acknowledgement of the occurrence. All investigators and key

REGULATORY SERVICES SERVICES
The University of Texas at Arlington, Center for Innovation

202 E. Border Street, Ste. 300, Arlington, Texas 76010, Box\#19188

(T) 817-272-3723 (F) 817-272-5808 (E) regulatoryservices@uta.edu (W) www.uta.edu/rs 


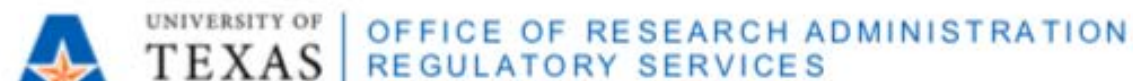

personnel identified in the protocol must have documented Human Subject Protection (HSP) Training on file with this office. Completion certificates are valid for 3 years from completion date.

The UT Arlington Office of Research Administration; Regulatory Services appreciates your continuing commitment to the protection of human research subjects. Should you have questions or require further assistance, please cont act Regulatory Services at regulatoryservices@uta.edu or 817-272-3723.

REGULATORY SERVICES SERVICES
The Univeriliy of Texas at Arlington, Center for innovation 202 E. Berder Street. Ste. 300, Anington, Texas 76010, Boxill1918.

(T) $817.272-3723$ (f) 8174725808 (E) regulatoryservices guta.edu (W) www.uta.edur 


\title{
APPENDIX B
}

\author{
UT Arlington \\ Informed Consent Document
}

\section{PRINCIPAL INVESTIGATOR}

Noelle L. Fields, PhD, LCSW, Assistant Professor

noellefields@uta.edu

School of Social Work, The University of Texas at Arlington, 211 South Cooper Street, Box 19129, Arlington, TX 76019

\section{CO-PRINCIPAL INVESTIGATORS}

Courtney Cronley, PhD, Associate Professor

cronley@uta.edu

School of Social Work

Stephen Mattingly, PhD, Associate Professor

mattingly@uta.edu

Department of Civil Engineering

Kate Hyun, PhD, Assistant Professor

kyung.hyun@uta.edu

Department of Civil Engineering

\section{TITLE OF PROJECT}

How can interdisciplinary teams leverage emerging technologies to respond to transportation infrastructure needs? A mixed-methods evaluation of civil engineers, urban planning, and social workers' perspectives.

\section{INTRODUCTION}

You are being asked to participate in a research study that explores how engineers, planners, and social workers interact around issues of transportation and transportation equity and to identify opportunities for enhanced collaboration and training in anticipation of emerging transportation needs for environmental justice (EJ) populations. Your participation in this research is completely voluntary. Refusal to participate or discontinuing your participation at any time will involve no penalty or loss of rights to which you are entitled. Please ask if you have any question at any time.

\section{PURPOSE}


The specific purpose of this research study is to lay the foundation for future educational research, identify strategies for using two Android apps (Safe Activity and My Amble) developed at UTA, and identify opportunities for collaborative solutions within the state-of-thepractice. Data will be collected through focus groups.

\section{DURATION}

You will be asked to participate in a focus group with other professionals (engineers, planners, and social workers). This focus group will discuss the training needs for improving transportation planning, and strategies and collaborative applications for Safe Activity and My Amble. The focus group will consist of a maximum of 6 professionals in the Dallas-Forth Worth metro area and one moderator. The anticipated length of the focus group is 2 hours. The focus group may be held online utilizing the Zoom program.

\section{NUMBER OF PARTICIPANTS}

Approximately 72 participants.

\section{POSSIBLE BENEFITS}

By participating in this study, you may not have any direct benefits; however, you will have the potential benefit of identifying solutions to address transportation barriers for EJ populations. Additionally, you may help contribute to the future development of interventions or systems that address transportation concerns of EJ populations.

\section{POSSIBLE RISKS/DISCOMFORTS}

Should you experience any discomfort, please inform the researcher. You have the right to quit any study procedure at any time with no consequence. The anticipated risks for participation in this study are minimal.

\section{COMPENSATION}

You will receive a $\$ 15$ gift card for participating in this study.

\section{PROCEDURES}

1) You will be assigned to a focus group. The dates, times, and locations of the focus group will be scheduled based on availability of the participants. The focus group may be held online utilizing the Zoom program. The focus groups will allow for open discussion among the participants, who will all be engineers, planners, and social workers in the Dallas Forth Worth area. While the discussion will be open, a moderator will ask probing questions to help facilitate the discussion. You are free to answer and respond, or not answer and not respond, to any of the probing questions without consequence. Focus groups will be audio recorded for transcription and analysis. Participation in this focus group will take approximately 2 hours. 


\section{ALTERNATIVE PROCEDURES}

There are no alternative procedures offered for this study. You can, however, elect not to participate in the study or may quit at any time without consequence.

\section{VOLUNTARY PARTICIPATION}

Participation in this research study is voluntary. You have the right to decline participation in any of all study procedures or quit at any time at without consequence. Your participation in this research study, or your refusal to participate in this research study, will not impact your employment.

\section{CONFIDENTIALITY}

Every attempt will be made to ensure that your study results are kept confidential. A copy of this signed consent form and all data collected from this study will be stored in the locked offices of Noelle Fields, PhD, LCSW in the University of Texas at Arlington School of Social Work for at least three years after the end of this research. Data collected will be anonymous (transcripts will not include names), password protected, and encrypted.

The results of this study may be published and/or presented at meetings without naming you as a participant; however, the results of the study will only provide a summary of the findings and will not include any information that will identify you as a participant (your name or your position and employer). Additional research studies could evolve from the information you have provided, but your information will not be linked to you in any way; it will be confidential. Although your rights and privacy will be maintained, the School of Social Work at the University of Texas at Arlington (UTA), the Department of Civil Engineering at UTA, the UTA Institutional Review Board (IRB), and personnel to this research have access to the study records. Your records will be kept completely confidential according to current legal requirements. They will not be revealed unless required by law, or as noted above. The IRB at UTA has reviewed and approved this study and the information within this consent form. If, in the unlikely event it becomes necessary for the IRB to review your research records, the University of Texas at Arlington will protect the confidentiality of those records to the extent permitted by law. By law, social workers are mandated reported reporters of suspected child and/or elder abuse or neglect. The only exception to confidentiality in this study is if there is a suspicion of abuse or neglect, and the researchers are mandated to report this to the appropriate State agency.

\section{CONTACT FOR QUESTIONS}

Questions about this research may be directed to Noelle Fields at (614) 947-9783. Any questions you may have about your rights as a research participant or a research-related injury may be directed to the Office of Research Administration; Regulatory Services at (817) 272-2105 or regulatoryservices@uta.edu.

As a representative of this study, I have explained the purpose, the procedures, the benefits, and the risks that are involved in this research study: 
Signature and printed name of principal investigator or person obtaining consent Date CONSENT

By signing below, you confirm that you are 18 years of age or older and have read or had this document read to you. You have been informed about this study's purpose, procedures, possible benefits and risks, and you have received a copy of this form. You have been given the opportunity to ask questions before you sign, and you have been told that you can ask other questions at any time.

You voluntarily agree to participate in this study. By signing this form, you are not waiving any of your legal rights. Refusal to participate will involve no penalty or loss of benefits to which you are otherwise entitled. You may discontinue participation at any time without penalty or loss of benefits to which you are otherwise entitled. 


\section{APPENDIX C}

\section{Focus Group Recruitment Script}

$\mathrm{Hi}$, my name is

(member of research team)

Thank you for allowing me to contact you about our transportation and EJ populations study. I would like to speak with you more about the study. Could we talk for a few minutes? If yes, the following will be presented:

I am a part of a research team at the University of Texas at Arlington that includes School of Social Work and Department of Civil Engineering. As a part of our study, we are conducting focus groups with transportation planners, social workers, and civil engineers about the transportation needs of EJ populations.

If you agree to be a volunteer in the study, you will be participating in a focus group via Zoom, a free online meeting platform. During the focus group, participants will be asked questions about how engineers, planners, and social workers interact around issues of transportation and transportation equity and to identify opportunities for enhanced collaboration and training in anticipation of emerging transportation needs for environmental justice (EJ) populations. We will digitally record the focus groups, but your privacy is very important and your private information will not be shared with anyone outside of the research project. The video will remain private and will only be viewed by members of the research team. This study has been approved by The University of Texas at Arlington and we will ensure to keep your information confidential.

As a part of the study, you will receive a $\$ 15.00$ gift card to Starbucks.

Would you be willing to be a part of this project? If yes, please tell me when we can meet to sign the consent form for this study. If no, thank you for your time. 


\section{APPENDIX D}

\section{Focus Group Demographics}

\section{Gender:}

Male

Female

Age:

21-25

26-30

41-45

31-35

46-50

36-40

51-55

56 or older

Race:

Black/African American

White

Hispanic

Asian

Other

Highest level of education:

High School Diploma

Some College

Associates Degree

Bachelors Degree

Masters Degree

Doctoral Degree

Major field of study

(e.g. social work, planning, engineering)

Occupation:

Social Worker

Engineer

Planner

Years in the profession

Licensure (yes/no)

Type

\section{Employer:}




\section{Focus Group Questions:}

1. What is the role of your profession in promoting transportation equity across communities, particularly for individuals who are at high risk of transportation disadvantages?

2. What skills/knowledge regarding transportation systems is required in your profession?

3. What tools do you lack that would better assist you in addressing transportation needs of environmental justice populations?

4. To what extent could engineers, planners, and social workers utilize the data and features within MyAmble/Safe Activity to accomplish their jobs more effectively?

5. To what extent do you interact with engineers, planners, and social workers regarding transportation infrastructure, decision-making, and policy?

6. What are the benefits you see in collaborating with engineers, planners, and social workers in the transportation planning process? 


\section{APPENDIX E}

\section{Phase 2, Small Starts Survey}

\section{Start of Block: Informed Consent (ICD)}

\section{Q1 PRINCIPAL INVESTIGATOR}

Noelle L. Fields, PhD, LCSW, Assistant Professor

noellefields@uta.edu

School of Social Work, The University of Texas at Arlington, 211 South Cooper Street, Box 19129, Arlington, TX 76019 ‘

CO-PRINCIPAL INVESTIGATORS Courtney Cronley, PhD, Associate Professor

cronley@uta.edu

School of Social Work

Kate Hyun, PhD, Assistant Professor

kyung.hyun@uta.edu

Department of Civil Engineering

\section{TITLE OF PROJECT}

How can interdisciplinary teams leverage emerging technologies to respond to transportation infrastructure needs? A mixed-methods evaluation of civil engineers, urban planning, and social workers’ perspectives.

\section{INTRODUCTION}

The transportation system impacts all members of society because it provides access to activities, which include all maintenance activities such as services and supports necessary for survival. While planners and engineers must seek to address environmental justice populations in their solutions, they may not have sufficient preparation to evaluate the impacts of different strategies on all community members. At the same time, social workers may recognize the importance of transportation for the clients that they serve, but they may not be aware of the decision-making processes, the broader approaches used to develop transportation solutions, or the costs 
associated with these solutions. All of these groups of professionals may be unaware of all of the tools available to them, and more importantly, unaware of the roles of other professionals.

\section{PURPOSE}

This study seeks to explore the current relationships and interactions between engineers, planners, and social workers, and to identify opportunities for collaboration and improved training for the future.

\section{DURATION}

This survey will take 20 to 30 minutes.

\section{NUMBER OF PARTICIPANTS}

250 individuals.

\section{POSSIBLE BENEFITS}

By participating in this study, you may not have any direct benefits; however, you will have the potential benefit of identifying solutions used by other professionals in overcoming transportation barriers. Additionally, you may help contribute to the future development of interventions or systems that address transportation concerns.

\section{POSSIBLE RISKS/DISCOMFORTS}

Should you experience any discomfort, please inform the researcher. You have the right to quit any study procedure at any time with no consequence. The anticipated risks for participation in this study are minimal.

\section{COMPENSATION}

You will not receive compensation for participation in this study.

\section{PROCEDURES}

You will be asked to complete a survey where you will be asked questions about accessing transportation systems. The anticipated length of the survey is less than 30 minutes.

\section{ALTERNATIVE PROCEDURES}

There are no alternative procedures offered for this study. You can, however, elect not to participate in the study or may quit at any time without consequence.

\section{VOLUNTARY PARTICIPATION}

Participation in this research study is voluntary. You have the right to decline participation in any of all study procedures or quit at any time at without consequence. Your participation in this research study, or your refusal to participate in this research study, will not impact your employment.

\section{CONFIDENTIALITY}

Every attempt will be made to ensure that your study results are kept confidential. All data collected from this study will be stored in the locked offices of Noelle Fields, PhD, in the University of Texas at Arlington School of Social Work for at least three years after the end of 
this research. Data collected will be anonymous (transcripts will not include names), password protected, and encrypted. The results of this study may be published and/or presented at meetings without naming you as a participant; however, the results of the study will only provide a summary of the findings and will not include any information that will identify you as a participant (your name or your position and employer). Additional research studies could evolve from the information you have provided, but your information will not be linked to you in any way; it will be confidential. Although your rights and privacy will be maintained, the School of Social Work at the University of Texas at Arlington (UTA), the Department of Civil Engineering at UTA, the UTA Institutional Review Board (IRB), and personnel to this research have access to the study records. Your records will be kept completely confidential according to current legal requirements. They will not be revealed unless required by law, or as noted above. The IRB at UTA has reviewed and approved this study and the information within this consent form. If, in the unlikely event it becomes necessary for the IRB to review your research records, the University of Texas at Arlington will protect the confidentiality of those records to the extent permitted by law. By law, social workers are mandated reported reporters of suspected child and/or elder abuse or neglect. The only exception to confidentiality in this study is if there is a suspicion of abuse or neglect, and the researchers are mandated to report this to the appropriate State agency.

\section{CONTACT FOR QUESTIONS}

Questions about this research may be directed to Noelle Fields at (614) 947-9783. Any questions you may have about your rights as a research participant or a research-related injury may be directed to the Office of Research Administration; Regulatory Services at (817) 272-2105 or regulatoryservices@uta.edu.

\section{CONSENT}

By clicking “ACCEPT" below, you confirm that you are 18 years of age or older and have read or had this document read to you. You have been informed about this study's purpose, procedures, possible benefits and risks, and you may print a copy of this form using the "Print" function in your browser. You have been given the opportunity to ask questions before you make a decision regarding your participation, and you have been told that you can ask other questions at any time. You voluntarily agree to participate in this study. By clicking “ACCEPT” below, you are not waiving any of your legal rights. Refusal to participate will involve no penalty or loss of benefits to which you are otherwise entitled. You may discontinue participation at any time without penalty or loss of benefits to which you are otherwise entitled.

ACCEPT; I voluntarily agree to participate in this survey

DECLINE; I choose to not participate in this survey (2) 
Q2 Gender:

Male (1)

Female (2)

Q4 What is your age?

Q5 How would you classify your race/ethnicity?

Arab (1)

Asian/Pacific Islander (2)

African-American/Black (3)

Caucasian/White (4)

Hispanic (5)

Indigenous/Aboriginal (6)

Lation/a (7)

Multiracial (8)

Prefer not to report (9)

Other: (10) 
Q6 Are you of Hispanic, Latino/a, or Spanish origin?

Yes (1)

No (2)

Q7 What is the highest level of education you have completed?

Some college (1)

Bachelor's degree (2)

Master's degree (3)

Doctoral degree (4)

Professional degree (5)

Other: (6)

Q19 How would you describe yourself professionally?

Social worker (1)

Transportation planner (2)

Civil engineer (3)

Other: (4) 
Q8 To what degree do you think transportation systems meet the needs of diverse populations, particularly individuals who are lower-income, older, or disabled?

To a very great extent (1)

To a great extent (2)

To a moderate extent (3)

To some extent (4)

To a small extent (5)

Not at all (6)

Q9 What types of transportation-related skills are important to your profession? (Select all that apply)

Data analysis (1)

Advocacy (2)

Brokering services (3)

Writing policies (4)

Engaging with the public (5)

All of the above (6)

None of the above (7)

Other: (8) 
Q10 What type of transportation-related knowledge is important for you in your job? (Select all that apply)

Available resources (e.g., discount fares, transit assistance) (1)

Transportation infrastructure or policy (2)

Disadvantaged, at-risk populations in need of transportation (3)

All of the above (4)

None of the above (5)

Other: (6)

Q11 To what extent can the following professions (Social Service, Civil Engineering, Transportation Planning) inform transportation system planning?

$\begin{array}{cccccc}\text { To a very } & \text { To a great } & \text { To a } & \text { To some } & \text { To a small } & \text { Not at all } \\ \text { great } & \text { extent (2) } & \begin{array}{c}\text { moderate } \\ \text { extent (3) }\end{array} & \text { extent (4) } & \text { extent (5) } & \text { (6) }\end{array}$

\section{Social Service \\ Providers (1) \\ Civil \\ Engineers (2) \\ Transportation \\ Planners (3)}
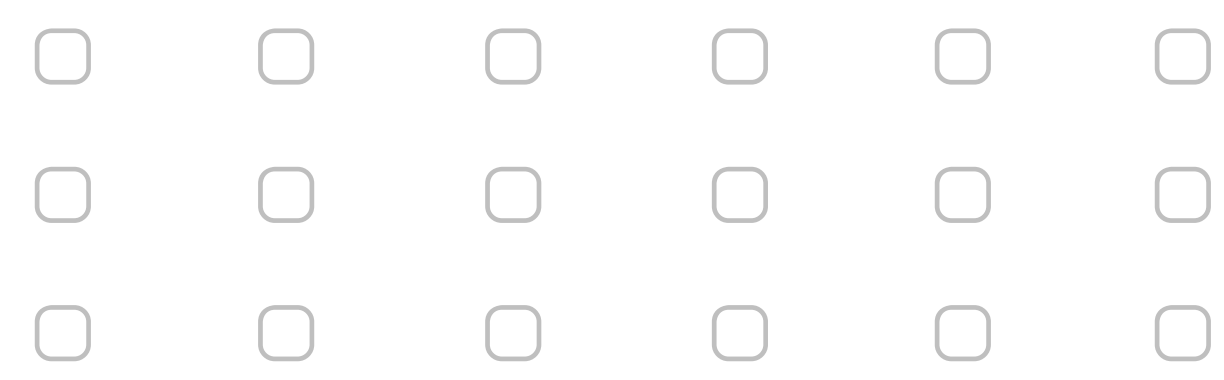
Q15 How frequently do you work with other disciplines/professions (Civil Engineers, Transportation Planners, Social Workers) to improve transportation infrastructure and policy?

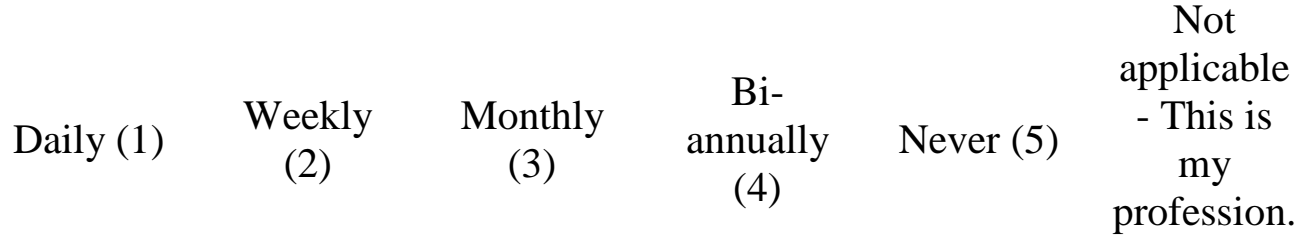

(6)

Civil
Engineers (1)
Transportation
Planners (2)
Social
Workers (3)

Q16 How important to you is working with other professions to improve transportation infrastructure and policy?

Extremely important (1)

Very important (2)

Moderately important (3)

Slightly important (4)

Not at all important (5) 
Q17 In what contexts or forums do you interact with other professions (Civil Engineers, Transportation Planners, Social Workers)? (select all that apply)

City Council (1)

Public Hearing Meeting (2)

Forums (3)

Workshops (4)

Local Conferences (5)

State Conferences (6)

National Conferences (7)

Other: (8)

Not applicable - I do not work with other professions. (9) 
Q19 For the purpose of collecting transportation activity data using a mobile device app, please rate each feature's utility as a function of the app. 
Extremely Very helpful Somewhat Slightly Not at all

Helpful (1) (2) Helpful (3) Helpful (4) Helpful (5)

\section{Crowd-}

sourced Data

(1)
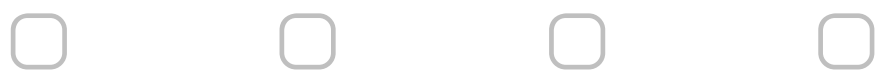

GPS to

pinpoint user

location (2)
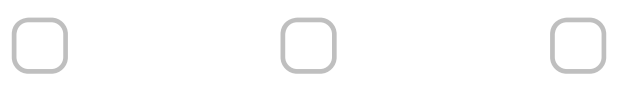

Interactive

map with

GPS (3)

Interactive

map without GPS (4)

Asynchronous features (i.e., users can

utilize the app and answer questions when they choose) (5)

Open-ended questions for users to provide responses of their choosing (6)

\section{Multi-lingual} text (7)

Embedded regional transportation resources that users can search for and utilize (8) 


Embedded
national
transportation
resources that
users can
search for and
utilize (9)
Questions
about user's
actual
transportation
mode (10)
Questions
about user's
preferred
transportation
mode (11)
Features that
capture
longitudinal
data (12)
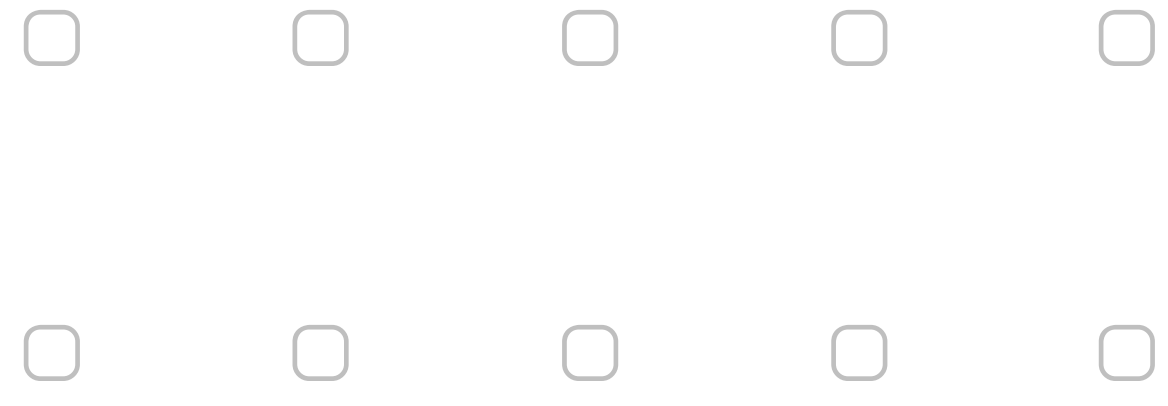
Q21 Please rate how helpful interdisciplinary collaborations would be for the following transportation infrastructure and policy decisions:

\begin{tabular}{|c|c|c|c|c|c|}
\hline & $\begin{array}{l}\text { Extremely } \\
\text { Helpful (1) }\end{array}$ & $\begin{array}{c}\text { Very } \\
\text { Helpful (2) }\end{array}$ & $\begin{array}{l}\text { Somewhat } \\
\text { Helpful (3) }\end{array}$ & $\begin{array}{c}\text { Slightly } \\
\text { Helpful (4) }\end{array}$ & $\begin{array}{c}\text { Not at all } \\
\text { Helpful (5) }\end{array}$ \\
\hline $\begin{array}{l}\text { For the } \\
\text { reputability and } \\
\text { rigor of future } \\
\text { research efforts } \\
\text { (1) }\end{array}$ & & & & & \\
\hline $\begin{array}{l}\text { To expand each } \\
\text { profession's } \\
\text { understanding of } \\
\text { transportation } \\
\text { planning within } \\
\text { the community (2) }\end{array}$ & & & & & \\
\hline $\begin{array}{c}\text { To improve } \\
\text { overall services } \\
\text { for EJ population } \\
\text { (3) }\end{array}$ & & & & & \\
\hline $\begin{array}{c}\text { For } \\
\text { engineers/planners } \\
\text { to communicate } \\
\text { with social } \\
\text { workers (4) }\end{array}$ & & & & & \\
\hline $\begin{array}{c}\text { For social workers } \\
\text { to communicate } \\
\text { with } \\
\text { transportation } \\
\text { engineers/planners } \\
\text { (5) }\end{array}$ & & & & & \\
\hline $\begin{array}{l}\text { To improve } \\
\text { transportation for } \\
\text { the overall } \\
\text { community (6) }\end{array}$ & & & & & \\
\hline
\end{tabular}


Q20 How beneficial do you think an interdisciplinary course related to transportation in your undergraduate or graduate studies would have been for your current work?

Very helpful (1)

Helpful (2)

Somewhat helpful (3)

Not that helpful (4)

Not at all helpful (5)

\section{End of Block: RQ4:}

\section{Start of Block: ADDL:}

Q22 To what extent would the following interdisciplinary classes or courses (classes with more than one discipline) have been useful to you at the undergraduate or graduate level?

\begin{tabular}{c|cc} 
& Yes (1) No (2) & Not Applicable (3) \\
\hline Interdisciplinary & & \\
courses with social & & \\
workers (1) & & \\
Interdisciplinary \\
courses with
\end{tabular}


Q23 What other interdisciplinary options were available for you in your undergraduate or graduate education (Select all that apply):

Internship/Field Placement/Practicum (1)

Research Activities (2)

Independent Studies (3)

Special Lectures (4)

Workshops (5)

Other: (6) 


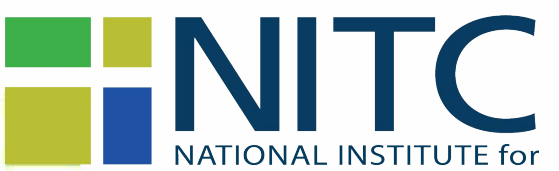

TRANSPORTATION and COMMUNITIES

Transportation Research and Education Center

Portland State University

1900 S.W. Fourth Ave., Suite 175

Portland, OR 97201 